\title{
A new approach to improve noncircular turning process
}

\author{
Piotr Sitarz ${ }^{1} \cdot$ Bartosz Powałka ${ }^{1}$
}

Received: 27 June 2016 / Accepted: 18 February 2019 / Published online: 4 July 2019

(C) The Author(s) 2019

\begin{abstract}
Processing efficiency optimization is often conducted in production environments. For turning, however, the introduction of noncircular cross-section workpieces generates new complexity. This paper presents the kinematic analysis and efficiency optimization of turning a noncircular cross-section workpiece on the basis of ISO 10208:1991 male rope thread machining, characterized by a smooth contour. This thread can be machined, for example, with standard thread turning or using X-axis motions characteristic of noncircular objects, i.e., rope threading. In that case, selecting the proper method and machining parameter values for efficiency can be more challenging than in circular cross-section workpiece turning. The latter method avoids many tool passes but requires highly dynamic movements of the machine in the X-axis. In addition to these two methods, a hybrid method is presented that is characterized by reduced dynamics in the $\mathrm{X}$-axis and more passes than the rope threading method. A description of the methods using mathematical parameters is developed to optimize the process efficiency. Numerical calculations to select a method and its associated cutting parameters are carried out for exemplary cutting edges, theoretical roughness values, tool life models, and other variables. The obtained results and the optimization algorithm of the process are presented.
\end{abstract}

Keywords Machining efficiency $\cdot$ Turning optimization $\cdot$ Noncircular turning $\cdot$ Thread machining $\cdot$ Rope threading

\section{Nomenclature}

Units taken for calculation are as below unless otherwise stated. They may have prefixes in tables or in figures presenting results.

$d \quad$ major thread diameter, $d \in\{d 1, d 2, d 3, d 4, d 5\}(\mathrm{mm})$

$P \quad$ thread pitch $(m)$

$h \quad$ thread depth $(m)$

$X, Z \quad$ machine coordinate system axes

$R_{1} \quad$ thread crest radius value $(\mathrm{m}), R_{1}=5.5 \cdot 10^{-3}(\mathrm{~m})$ for the analyzed thread

$R_{2} \quad$ thread root radius value $(\mathrm{m}), R_{2}=6 \cdot 10^{-3}(\mathrm{~m})$ for the analyzed thread

$R \quad$ thread geometry radius, $R \in\left\{R_{1}, R_{2}\right\}(m)$

Piotr Sitarz

piotr_sitarz@zut.edu.pl

Bartosz Powałka

bartosz.powalka@zut.edu.pl

1 Faculty of Mechanical Engineering and Mechatronics, West Pomeranian University of Technology, Piastów 19,

70-310 Szczecin, Poland $a_{x} \quad$ maximum tool acceleration value in the $\mathrm{X}$-axis during machining $\left(\frac{m}{s^{2}}\right)$

$R z \quad$ surface roughness $(\mu m)$

$f_{z} \quad$ feed rate in the Z-axis $(m)$

$r_{\varepsilon} \quad$ tool nose radius value $(m)$

$n \quad$ rotational spindle speed $(\mathrm{rpm})$

$a_{M} \quad$ maximum tool acceleration value in the $\mathrm{X}$-axis for the machine $\left(\frac{m}{s^{2}}\right)$

$\mathrm{Z}^{\prime} \quad$ axis of thread rotation transformed into a linear form

$v_{z^{\prime}} \quad$ speed component resulting from rotational spindle speed $n$ and from feed $f_{z}\left(\frac{m}{s}\right)$

$\varphi \quad$ angle of spindle revolution ( $\mathrm{rad}$ )

$t$ time recorded from the time point that the tool was at point $A_{1}(s)$

$A_{1}, A_{2} \quad$ points on a tool path where $v_{x}=0$

$B_{1}, B_{2}$ points on a tool path at the tangential point of arcs and a straight line

$v_{x} \quad$ speed component in the $\mathrm{X}$-axis $\left(\frac{m}{s}\right)$

$z^{\prime} \quad$ translation in $Z^{\prime}$-axis $(m)$

$\beta \quad$ angle that define the position of a cutting tool on the $\operatorname{arcs}\left({ }^{\circ}\right)$

$\beta_{1}, \beta_{2} \quad$ angles that define the position of a cutting tool on the $\operatorname{arcs}\left({ }^{\circ}\right)$, respectively, $A_{1} B_{1} A_{2} B_{2}, \beta_{1} \in(0, \alpha)$, $\beta_{2} \in(\alpha, 0)$ 
$\alpha \quad$ inclination angle of a tangent connecting the $\operatorname{arcs} A_{1} B_{1}, B_{2} A_{2}$ (Fig. 3a) ( ),$\alpha \approx 19^{\circ}$ for the analyzed thread, and the rounded number is taken for the calculations

$a_{x 1} \quad$ tool acceleration value in the $\mathrm{X}$-axis on arcs defined by radius $R_{1}\left(\frac{m}{s^{2}}\right)$

$a_{x 2} \quad$ tool acceleration value in the $\mathrm{X}$-axis on arcs defined by radius $R_{2}\left(\frac{m}{s^{2}}\right)$

$t_{A 1} \quad$ time when the conducted analysis starts, when the tool is in point $A_{1}$, equal to zero for further calculations $(s)$

$t_{A 2}$ time recorded from the moment the tool moves from $A_{1}$ to $A_{2}(s)$

$t_{B 1} \quad$ time recorded from the moment the tool moves from $A_{1}$ to $B_{1}(s)$

$t_{B 2}$ time recorded from the moment the tool moves from $A_{1}$ to $B_{2}(\mathrm{~s})$

$T_{\text {rev }}$

$a_{\max } x$

$a_{\max x 2}$

$a_{R 1}$

$a_{R 2}$

$v_{x_{A_{1}}}$

$v_{x_{B_{1}}}$

$\Delta z_{1}^{\prime}$

spindle rotation period $(s)$

maximum acceleration value for $t \in\left(t_{A 1}, t_{B 1}\right)\left(\frac{m}{s^{2}}\right)$

maximum acceleration value for $t \in\left(t_{B 2}, t_{A 2}\right)\left(\frac{m}{s^{2}}\right)$

average acceleration equation in the $\mathrm{X}$-axis on the arc defined by radius $R_{1}$

average acceleration equation in the $\mathrm{X}$-axis on the arc defined by radius $R_{2}$

tool speed in the $\mathrm{X}$-axis at point $A_{1}$ equal to zero $\left(\frac{m}{s}\right)$ tool speed in the $\mathrm{X}$-axis at point $B_{1}\left(\frac{m}{s}\right)$

travelled section along $Z^{\prime}$-axis in which the center of a circle in the tool nose travels from point $A_{1}$ to point $B_{1}(m)$

$\Delta z_{2}^{\prime} \quad$ travelled section along $Z^{\prime}$-axis in which the center of a circle in the tool nose travels from point $B_{2}$ to point $A_{2}(\mathrm{~m})$

$x \quad$ translation in $\mathrm{X}$-axis $(m)$

$a_{e} \quad$ cutting width $(m)$

$t_{1} \quad$ time of machining the element in rope threading without accounting for tool life ( $\mathrm{min}$ )

$l \quad$ length of a machined thread in the Z-axis $(m)$

$n_{a \max }$ limitation of the maximum rotational spindle speed

(rpm), determined by $a_{M}$, for $m=1$

$v_{c} \quad$ cutting speed $\left(\frac{m}{\min }\right)$

$v_{c \text { min }}, \quad$ constraints of the cutting speed $\left(\frac{\mathrm{m}}{\mathrm{min}}\right)$

$v_{c \max }$

$n_{\text {min }}$

limitation of the minimum spindle speed (rpm) corresponding to the limitation of the minimum cutting speed value $v_{c}$ min

$n_{v \max } \quad$ limitation of the maximum rotational spindle speed (rpm), determined by $v_{c \max }$, for $m=1$

$n_{\max } \quad$ limitation of the maximum rotational spindle speed (rpm) determined by $a_{M}$ and $v_{c \max }$, defined by (22), for $m=1$ time of machining the element in rope threading (min), considering the tool life dependent on the cutting speed $v_{c}$ and dependent on both cutting speed $v_{c}$ and feed rate $f_{z}$

tool exchange time ( $\mathrm{min}$ )

number of operations over the cutting tool life cutting tool life ( $\mathrm{min}$ ) as a function of $v_{c}$

constant that mathematically corresponds to the tool life ( $\mathrm{min}$ ) at a cutting speed of $v_{c}=1\left(\frac{\mathrm{m}}{\mathrm{min}}\right)$

$k \quad$ constant dependent on the cutting tip material and cutting edge failure criterion

$T_{v q} \quad$ optimum tool life ( $\mathrm{min}$ ) considering the tool life dependent on the cutting speed $v_{c}$

$n_{o p t_{T_{v}}}$ optimum rotational spindle speed for $m=1$, accounting for the tool life dependent on the cutting speed $v_{c}$ before constraint consideration $\left(\frac{\mathrm{m}}{\mathrm{min}}\right)$

$n_{\text {opt } v} \quad$ optimum rotational spindle speed for $m=1$, accounting for the tool life dependent on the cutting speed $v_{c}$ with constraint consideration $\left(\frac{\mathrm{m}}{\mathrm{min}}\right)$

$T_{v, f} \quad$ cutting tool life ( $\mathrm{min}$ ) as a function of $v_{c}$ and $f_{z}$

$y_{T}$ coefficient that defines the effect of the feed rate $f_{z}$ on the tool life

$n_{o p t_{T_{v, f}}}$ optimum rotational spindle speed for $m=1$, accounting for the tool life dependent on the cutting speed $v_{c}$ and Z-axis feed rate $f_{z}$ before constraint consideration $\left(\frac{\mathrm{m}}{\mathrm{min}}\right)$

$n_{\text {opt }} v_{f} \quad$ optimum rotational spindle speed relative to the tool life dependent on the cutting speed $v_{c}$ and Z-axis feed rate $f_{z}$ with constraint consideration $\left(\frac{\mathrm{m}}{\mathrm{min}}\right)$

$m \quad$ number of tool passes in the machining process of a single element $m \in<1,\left|\frac{P}{a_{e}}\right|>$ and $m$ is a positive integer and $\left\lfloor\frac{P}{a_{e}}\right\rfloor$ denotes the floor function of $\left\lfloor\frac{P}{a_{e}}\right\rfloor$

$R z_{1}, R z_{2}$, roughness depending on the type of rectilinear sec-

$R z_{3} \quad$ tion of the tool path $(\mu m)$

$t_{3} \quad$ time required to machine a thread in $m$ tool passes without considering the tool life $(\mathrm{min}$ )

$v_{m} \quad$ speed of tool positioning movements $\left(\frac{\mathrm{m}}{\mathrm{min}}\right)$

$t_{p} \quad$ tool input time or tool output time ( $\mathrm{min}$ )

$u \quad$ variable specifying additional tool passes

$n^{\prime}, n^{\prime \prime} \quad$ rotational spindle speed in machining with $m$-passes and $m+y$ passes, respectively $\left(\frac{\mathrm{m}}{\min }\right)$

$t_{4} \quad$ machining time of the thread considering the tool life and tool exchange time $(\mathrm{min})$

$T \quad$ tool life equal to $T_{v}(26)$ or $T_{v, f}$ (30) ( $\mathrm{min}$ )

$n_{\text {opt }} \quad$ optimum rotational spindle speed accounting for tool life before increasing the number of tool passes-for $m=1, n_{\text {opt }} \in\left\{n_{\text {opt } v}, n_{\text {opt } v, f}\right\}$

$m_{\text {opt }} \quad$ optimum number of tool passes depending on the tool life model, $m_{\text {opt }} \in\left\{m_{v}, m_{v}, f\right\}$

$n_{\text {opt }}^{\prime} \quad$ optimum rotational spindle speeds for $m_{o p t}, n_{o p t} \in$ $\left\{n_{\text {opt } v}^{\prime}, n_{\text {opt } v, f}^{\prime}\right\}(\mathrm{rpm})$ 
$t_{4 v} \quad$ shortest time ( $\mathrm{min}$ ) of machining with optimum parameters, taking into account $T_{v}$

$t_{4 v, f} \quad$ shortest time ( $\mathrm{min}$ ) of machining with optimum parameters, taking into account $T_{v, f}$

$m_{v} \quad$ optimum number of tool passes taking into account the tool life $T_{v}, m_{v} \in<1,\left|\frac{P}{a_{e}}\right|>$ and $m_{v}$ is a positive integer

$m_{v, f} \quad$ optimum number of tool passes taking into account the tool life $T_{v, f}, m_{v, f} \in<1,\left|\frac{P}{a_{e}}\right|>$ and $m_{v, f}$ is a positive integer

$n_{\text {opt } v}^{\prime} \quad$ optimum rotational spindle speed $(\mathrm{rpm})$ taking into account the tool life $T_{v}$ for $m=m_{v}$

$n_{\text {opt } v f}$ optimum rotational spindle speed ( $\mathrm{rpm}$ ) taking into account the tool life $T_{v, f}$ for $m=m_{v f}$

$p\left(R_{z}, r_{\varepsilon}\right)$ successive pairs of roughness classes radius $r_{\varepsilon}$ as a domain of graphs from Figs. 15 and 16 and tool nose

$n_{a \max v}^{\prime} \quad$ limitation of the maximum rotational spindle speed (rpm), determined by $a_{M}$, for $m_{v}$

$n_{a \text { max } v, f}^{\prime}$ limitation of the maximum rotational spindle speed $(r p m)$, determined by $v_{c \max }$, for $m_{v, f}$

\section{Introduction}

Noncircular turning (also known as radial contour turning) is a single-point cutting process that generates workpieces with noncircular cross sections. This turning method is frequently used in machining industrial parts such as camshafts [1] and piston heads [2-7]. The noncircular section is realized by moving a tool along the radial direction, synchronous with the workpiece rotation. The radial motion of the tool is typically implemented by a special servo tool stage. In such cases, the possibilities of efficient machining are typically limited by the ability to follow the given trajectory. Many technical solutions have been developed to ensure the best possible dynamics; some of them use voice coil actuators $[6,8]$ or piezoelectric actuators $[2,4,9]$. The high-frequency synchronization of the radial motion of the turning tool with the rotation of the spindle also poses a challenge to the control system [3]. Over the years, many papers have been published about this subject [1, 2, 5-8, $10,11]$. In [8], the tracking performances of acceleration and force-feedback controllers were investigated. Wu and Chen [6] and $\mathrm{Wu}$ et al. [7] addressed time-varying dynamics, cutting force disturbances, and other uncertainties and proposed the concept of disturbance rejection control. Another approach by researchers Wang and Yang [2], and Hanson RD and Tsao T-C [10] focused on using repetitive control to minimize tracking error in machining an ellipse piston. A two-level control structure composed of servo control and frequency-domain learning control was used by Sun and Tsao [1]. Wu, Chen, and Wang analyzed the process for stability [11] and investigated variable spindle speed machining. Qiang, Wu, and Bing [5] studied noncircular turning also from the cutting process standpoint and proposed a spindle control with variable speed and the variable angle compensation mechanism, aiming to maintain a constant rake angle and velocity during oval piston machining. In contrast to pistons and camshafts, rope threads can typically be manufactured using both methods, i.e., noncircular turning (rope threading) and classical circular turning (standard threading). Application of the former requires only one pass of the tool, whereas the latter requires multiple tool passes performed at various diameters. This may lead to the question of which of these methods is more efficient, because high-performance turning is also an issue being studied [12-14]. Lee and Tarng [12] presented a sequential quadratic programming method for minimizing the production cost and maximizing its rate in multistage turning operation. In [14], Paiva et al. applied multivariate optimization to maximize the material removal rate and minimize the cutting time, costs, cycle time, and surface roughness. Additionally, they took into account the tool life, which is typically considered an important performance index when optimizing turning parameters [13, 15-18]. Another issue related to the optimization of the turning process is the surface roughness, which depends primarily on the tool geometry and preset feed rate [19-22]. To formulate the efficiency optimization issue for the rope threads, it is required to analyze the kinematics of the rope threading method, which is different from the classical turning. The analysis was made in the present paper. To optimize the machining process of the rope threads, the present paper describes the kinematic analysis of the rope threading process and presents the optimization taking into account the desired surface roughness, relationship between the nose radius and maximum tool acceleration of the tool motion, and (optionally) the chosen tool life model. The issue of possible shape errors was also discussed. Furthermore, next to the mentioned standard threading and rope threading, the paper puts forward a new hybrid threading method, which is a compromise between many tool passes characteristic for standard threading vs. singlepass machining. Obtained results and the algorithm of the machining efficiency optimization, for the given constraints and described tool life models, are presented. This paper is organized as follows. In Section 2, the theoretical background of the issue is presented. Performance optimization of rope threading without considering the tool life and with two tool life models is shown in Section 3. In Section 4, the machining methods, rope/standard/hybrid threading, are analyzed. In Section 5, an algorithm for selecting cutting parameters and threading method is presented. The calculated efficiency results are shown in Section 6. Conclusions are given in Section 7. 


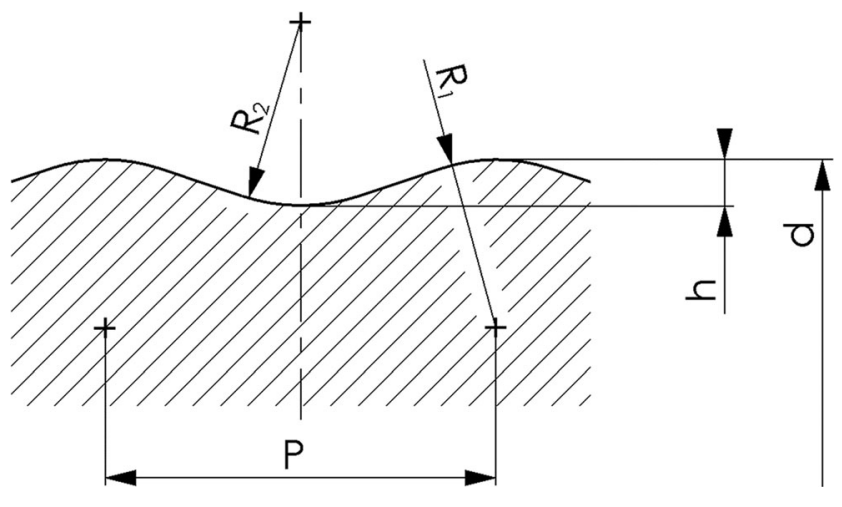

Fig. 1 Contour of a male thread based on ISO 10208:1991

\section{Theoretical background}

\subsection{Male thread based on ISO 10208:1991}

A contour of a male thread based on ISO 10208:1991 is presented in Fig. 1. The standard gives different thread diameters measured in $d$. The dimension values are shown in Table 1.

The contour is made up of arcs linked with a straight line tangent to each of them. The thread pitch is defined by $P$, and the thread depth is defined by $h$.

\subsection{Machining methods of the thread}

There are two typical turning methods for thread machining: standard threading and rope threading, as shown in Fig. 2. Standard thread machining requires many passes of a tool, and the feed rate is equal to the thread pitch. This method uses a relatively slow spindle speed and a relatively high Z-axis feed rate. The tool placement in the $\mathrm{X}$-axis is set to be constant during the pass. The use of many positioning movements after each pass increases machining time. In contrast to the standard threading method, rope threading requires only one pass of a tool, and the

Table 1 Values of the thread dimensions

\begin{tabular}{lll}
\hline $\begin{array}{ll}\text { Dimension } \\
\text { value }(\mathrm{mm})\end{array}$ & $\begin{array}{l}\text { Tolerances } \\
(\mathrm{mm})\end{array}$ \\
\hline$R_{1}$ & 5.5 & +0.4 \\
& & -0.4 \\
$R_{2}$ & 6 & +0.4 \\
& & -0.4 \\
$h$ & 1.5 & +0.4 \\
$P$ & 12.7 & -0.4 \\
$d$ & $d 1=21.84, d 2=24.74, d 3=27.95$, & - \\
& $d 4=31.34, d 5=37.99$ & -0.2 \\
\hline
\end{tabular}

feed rate in the Z-axis is smaller. However, tool movements in the $\mathrm{X}$-axis must be implemented, and high accelerations are required to ensure efficient machining. For rope threading, suitable dynamic properties of a lathe drive responsible for the $\mathrm{X}$-axis feed are typically the main constraint.

Both methods have their advantages and disadvantages. Standard threading requires time for tool return to avoid high dynamic movements in the $\mathrm{X}$-axis. Rope threading does not need multiple passes of the tool, but its efficiency is often constrained by dynamic tool motion limitations. Therefore, a third method is proposed: hybrid threading, which achieves a favorable balance between both methods described above. In this method, the number of tool passes is less than in standard threading but more than one (as in rope threading). As a result, high accelerations of rope threading and the high feed rate in the Z-axis of standard threading are both mitigated. Detailed tool movements of the three methods are described in Section 4.

\subsection{Rope threading modelled as a dynamic system}

It is possible to control certain machining parameters affecting the tool acceleration in the X-axis $a_{x}$ and the surface roughness $R z$ by the input cutting parameters. Because of that, the turning machine model in rope threading can be treated as a dynamic system. In the rope threading, the input parameters affecting the mentioned $a_{x}$ and $R z$ can be distinguished as feed per revolution $f_{z}$ and tool tip geometry with radius $r_{\varepsilon}$. The input parameter which additionally affects the $a_{x}$ is the rotational spindle speed $n$. Furthermore, the model is also time dependent as the output parameter values change during machining because of the influence of object geometry. It is assumed that for each machine, it is possible to determine the maximum acceleration of the $\mathrm{X}$-axis$a_{M}$. The maximum acceleration depends on the feed drive construction and the dynamic properties of the components and lathe control system. Based on the expected $R_{z}$ and determined $a_{M}$, the input controllable parameters can be optimized.

\subsection{Determination of accelerations in rope threading}

Rotational movement of a workpiece can be idealized as a tool moving linearly along a thread contour because the analyzed rope thread is a single-start thread form, i.e., the pitch and lead are equal.

The tool path in the $\mathrm{X}$-axis for one spindle revolution at constant speed is presented in Fig. $3 \mathrm{a}$ as the tool path along a profile in the $Z^{\prime}$-axis. When the thread is rotating in the spindle, the theoretical profile of the XZ-plane cross section appears to move along the $\mathrm{Z}$-axis (in the area constrained by the thread length). To describe that movement relative to the tool movement in the $\mathrm{Z}$-axis, the $\mathrm{Z}^{\prime}$ axis is introduced. Figure $3 \mathrm{a}$ shows the relative movements conducted by the tool. The relative speed of this motion is designated $v_{z^{\prime}}$. Depending on the directions of the spindle and feed motion of the tool in the 


\section{a}

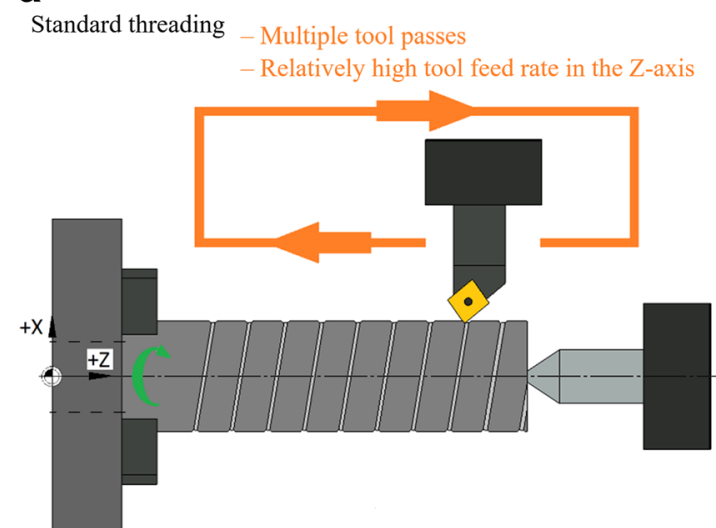

b

Rope threading

- Single tool pass

- High accelerations in the $\mathrm{X}$-axis

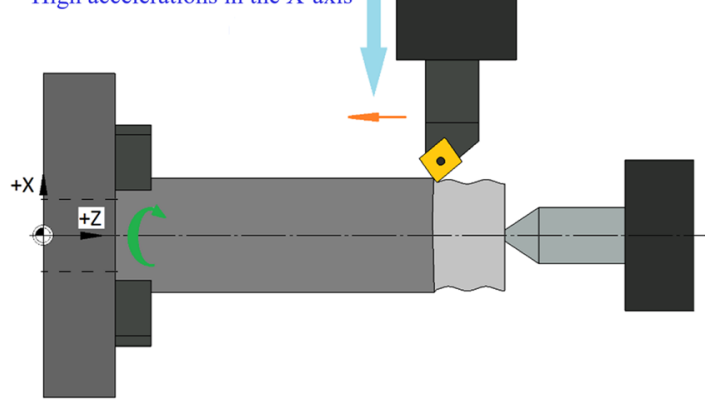

Fig. 2 Typical solutions for smooth contour thread turning. a Standard threading. b Rope threading

Z-axis, this speed may have two different values. Correctly selected directions of the rotational spindle speed and feed motion result in a smaller $v_{z^{\prime}}$ value.

The $Z^{\prime}$-axis corresponds to the angle of spindle revolution $\varphi$ or time $t$ given a constant spindle speed. The vertical axis in Fig. 3a defines displacements in the X-axis direction of the lathe. The tool path is separated from the thread contour by the value of the nose radius. Considering section $A_{1} A_{2}$, the tool accelerates in the $\mathrm{X}$-axis along $\operatorname{arcs} A_{1} B_{1}$ and $B_{2} A_{2}$. In section $B_{1} B_{2}$, the tool moves along the $\mathrm{X}$-axis with a constant speed. Further tool positions during machining replicate or flip this basic movement relative to the $\mathrm{X}$-axis. The relation between the vectors $v_{z^{\prime}}$ and $v_{x}$ is presented in the Fig. $3 b$.

Accelerations on arcs vary. The tool speed at each point is the resultant of the speeds $v_{x}$ and $v_{z^{\prime}}$ and is tangent to the tool path. Therefore, the relations between speed vectors are defined by angles $\beta_{1}$ and $\beta_{2}$ which are described by $\beta$ in Eq. (1), according to Fig. $3 b$. The speed in the $\mathrm{X}$-axis can be given by $v_{x}=-v_{z^{\prime}} \cdot \operatorname{tg}(\beta), \quad \beta=\left\{\begin{array}{l}\beta_{1}, \text { for } \operatorname{arc} R_{1} \\ \beta_{2}, \text { for } \operatorname{arc} R_{2}\end{array}\right.$

Angle $\beta_{1}$ presented in Fig. $3 \mathrm{a}$ as an arc defined by radius $R_{1}$ can be written as

$\beta_{1}=\arcsin \left(\frac{v_{z^{\prime}} \cdot t}{R_{1}+r_{\varepsilon}}\right)$

For an angle $\beta_{2}$ defined as tool angular position from point $B_{2}$ on an arc defined by radius $R_{2}$, the equation can be determined as

$\beta_{2}=\arcsin \left(\frac{\frac{P}{2}-v_{z^{\prime}} \cdot t}{R_{2}-r_{\varepsilon}}\right)$

Substituting Eqs. (2) and (3) into Eq. (1) and differentiating the result, we obtain Eqs. (4) and (6), which define
Fig. 3 Analysis of kinematics in rope threading. a Tool path analysis. b Dependence between tool speed vectors

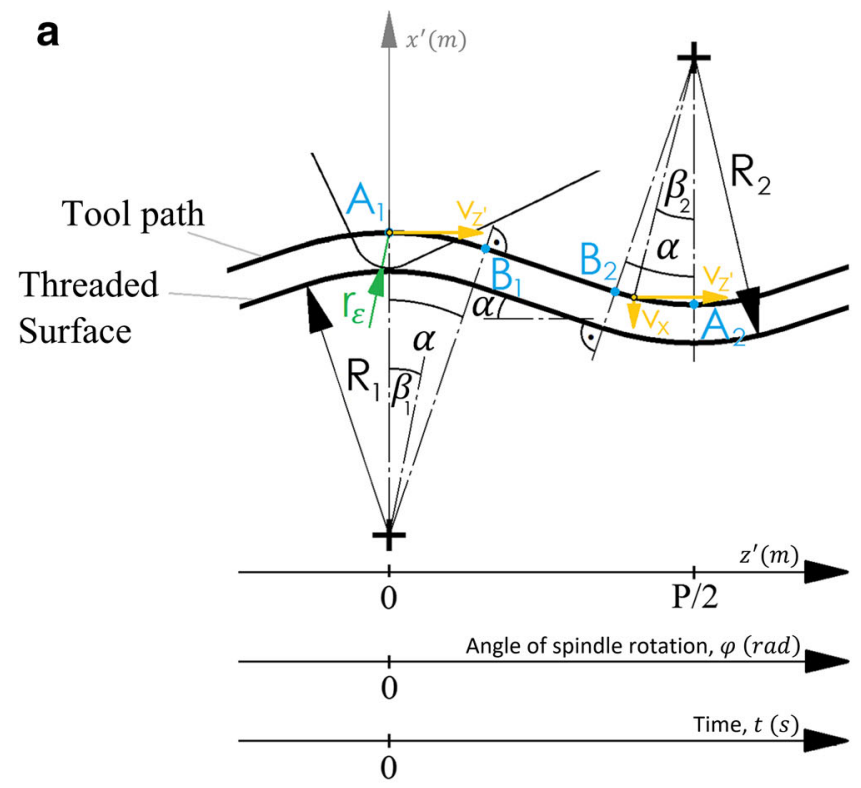

b

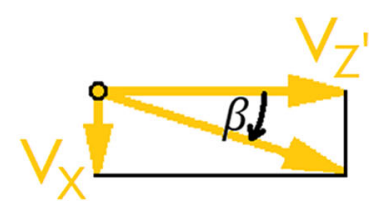


the tool acceleration in the $\mathrm{X}$-axis on arcs defined by radii $R_{1}$ and $R_{2}$, respectively: $a_{x 1}$ (4) and $a_{x 2}$ (6). The section that connects both thread arcs defined by radii $R_{1}$ and $R_{2}$ is tangent to the arcs and is a straight line, which means that tool acceleration in the $\mathrm{X}$-axis in this section is zero, as described by Eq. (5).

For $t \in\left(0, t_{B 1}\right)\left(\operatorname{arc} A_{1} B_{1}\right)$ :

$$
\begin{aligned}
a_{x 1}=\frac{d v_{x}\left(\beta_{1}\right)}{d t}= & -v_{z^{\prime} \cdot}\left(1+\left[\operatorname{tg}\left(\arcsin \left(\frac{v_{z^{\prime}} \cdot t}{R_{1}+r_{\varepsilon}}\right)\right)\right]^{2}\right) \\
& \cdot\left[1-\left(\frac{v_{z^{\prime}} \cdot t}{R_{1}+r_{\varepsilon}}\right)^{2}\right]^{-\frac{1}{2}} \cdot \frac{v_{z^{\prime}}}{R_{1}+r_{\varepsilon}}
\end{aligned}
$$

For $t \in\left(t_{B 1}, t_{B 2}\right)$ (section $\left.B_{1} B_{2}\right)$ :

$$
a_{x_{B 1 B 2}}=0
$$

For $t \in\left(t_{B 2}, t_{A 2}\right)\left(\operatorname{arc} B_{2} A_{2}\right)$ :

$$
\begin{aligned}
a_{x 2}=\frac{d v_{x}\left(\beta_{2}\right)}{d t}= & -v_{z^{\prime}} \cdot\left(1+\left[\operatorname{tg}\left(\left[\arcsin \left(\frac{\frac{P}{2}-v_{z^{\prime}} \cdot t}{R_{2}-r_{\varepsilon}}\right)\right]\right)\right]^{2}\right) \\
& \cdot\left[1-\left(\frac{P}{\frac{P}{2}-v_{z^{\prime}} \cdot t}\right)^{2}-r_{\varepsilon}\right)^{-\frac{1}{2}} \cdot \frac{-v_{z^{\prime}}}{R_{2}-r_{\varepsilon}}
\end{aligned}
$$

When the directions of spindle rotations and feed $f_{z}$ are correctly set, the tool does not pass over the whole contour in one spindle revolution, and its value is decreased by $f_{z}$. The results are presented in Fig. 4, which are schematic and may not fully reflect the real relations between dimensions of analyzed objects.

The speed values $v_{z^{\prime}}\left(\frac{\mathrm{m}}{\mathrm{s}}\right)$ can be given by

$v_{z^{\prime}}=\frac{P-f_{z}}{T_{\mathrm{rev}}}=\frac{\left(P-f_{z}\right)}{\frac{60}{n}}=\left(P-f_{z}\right) \cdot \frac{n}{60}$

Having substituted Eq. (7) into Eqs. (4) and (6) and having assumed angle $\beta=\alpha$ correlating with positions of maximum acceleration, we obtain equations of maximum acceleration on radii $R_{1}$ and $R_{2}$, as shown in Eqs. (8) and (9).

For $t \in\left(t_{A 1}, t_{B 1}\right)$ :

$$
\begin{aligned}
a_{\max x 1}= & \frac{d v_{x}\left(\beta_{1}=\alpha\right)}{d t}=-\left(P-f_{z}\right) \cdot \frac{n}{60} \cdot\left(1+(\operatorname{tg}(\alpha))^{2}\right) \\
& \cdot\left[1-(\sin (\alpha))^{2}\right]^{-0.5} \cdot \frac{\left(P-f_{z}\right) \cdot \frac{n}{60}}{R_{1}+r_{\varepsilon}}
\end{aligned}
$$

For $t \in\left(t_{B 2}, t_{A 2}\right)$ :

$$
\begin{gathered}
a_{\max x 2}=\frac{d v_{x}\left(\beta_{2}=\alpha\right)}{d t}=-\left(P-f_{z}\right) \cdot \frac{n}{60} \cdot\left(1+(\operatorname{tg}(\alpha))^{2}\right) \\
\cdot\left[1-(\sin (\alpha))^{2}\right]^{-0.5} \cdot \frac{-\left(P-f_{z}\right) \cdot \frac{n}{60}}{R_{2}-r_{\varepsilon}}
\end{gathered}
$$

These accelerations occur at points $B_{1}$ and $B_{2}$.
Absolute accelerations on each arc are presented in Fig. 5 in the time domain. Due to jerk limitation in each feed drive system, the profile can never actually be perfectly copied due to sudden acceleration increases at the beginning and the end of each arc. It is therefore assumed that the acceleration value of each machine $a_{M}$ can be defined as the average acceleration on a given arc. The average accelerations on sections $A_{1} B_{1}$ and $B_{2} A_{2}$ are equal to the average acceleration along the whole length of $\operatorname{arcs} R_{1}$ and $R_{2}$, respectively.

The average acceleration on an arc defined by radius $R_{1}$ can be given by

$a_{R 1}=\frac{\Delta v_{x}}{t_{B 1}-t_{A 1}}=\frac{v_{x_{1}}-v_{x_{A_{1}}}}{t_{B 1}-t_{A 1}}=\frac{v_{x_{B_{1}}}}{t_{B 1}-t_{A 1}}$, because $v_{x_{A_{1}}}=0$

The speed $v_{x_{1}}$ can be determined from Eqs. (1) and (7)

$v_{x_{B_{1}}}=\left(P-f_{z}\right) \cdot \frac{n}{60} \cdot \operatorname{tg}(\alpha)$

The time in which the center of the tool nose travels from point $A_{1}$ to point $B_{1}$ can be determined by dividing the travelled section along axis $Z^{\prime}$, by constant speed $v_{z^{\prime}}$ given by Eq. (7)

$t_{B 1}-t_{A 1}=\frac{\Delta z_{1}^{\prime}}{v_{z^{\prime}}}=\frac{\left(R_{1}+r_{\varepsilon}\right) \cdot \sin (\alpha)}{\left(P-f_{z}\right) \cdot \frac{n}{60}}$

After substituting Eqs. (11) and (12) into Eq. (10), we obtain the average acceleration equation in the $\mathrm{X}$-axis on the arc defined by radius $R_{1}$

$a_{R 1}=\frac{\left(P-f_{z}\right)^{2} \cdot\left(\frac{n}{60}\right)^{2}}{\left(R_{1}+r_{\varepsilon}\right) \cdot \cos (\alpha)}$

The time in which the center of a circle in tool nose travels from point $B_{2}$ to point $A_{2}$ can be determined by dividing the travelled section along $Z^{\prime}$-axis by the speed constant $v_{z^{\prime}}$ given by Eq. (7)

$t_{A 2}-t_{B 2}=\frac{\Delta z_{2}^{\prime}}{v_{z^{\prime}}}=\frac{\left(R_{1}-r_{\varepsilon}\right) \cdot \sin (\alpha)}{\left(P-f_{z}\right) \cdot \frac{n}{60}}$

The average acceleration on an arc defined by radius $R_{2}$ can be found in a similar way

$a_{R 2}=\frac{\left(P-f_{z}\right)^{2} \cdot\left(\frac{n}{60}\right)^{2}}{\left(R_{2}-r_{\varepsilon}\right) \cdot \cos (\alpha)}$

The tool path is dependent on the tool nose radius $r_{\varepsilon}$ because of the distance that separates the center of a circle defining the nose from the workpiece. Figure 6a presents tool paths for different values of $r_{\varepsilon}$ in rope threading defined by the standard. Rope threading is possible only for $r_{\varepsilon}<R_{2}$. The acceleration $a_{R 1}$ decreases with increasing nose radius $r_{\varepsilon}$, but the value of $a_{R 2}$ increases. Figure $6 \mathrm{~b}$ presents the values of: 

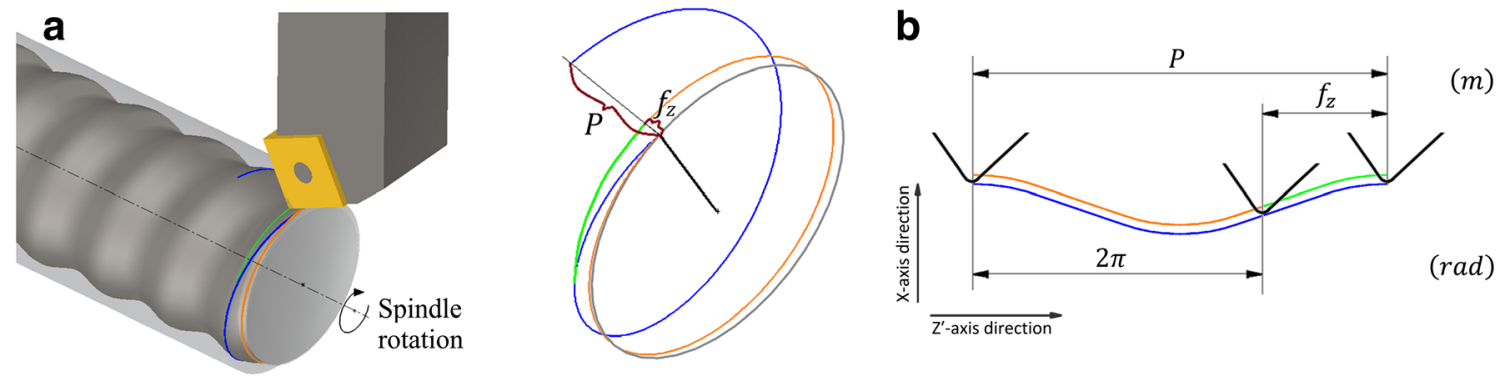

Fig. 4 The influence of $f_{z}$ on the tool movements in $Z^{\prime}$-axis. The following colors refer to the online version: Blue - thread helix; orange-part machined in one spindle revolution; green — part that had not been machined equal to $f_{z} / P ; P$ - thread pitch. a Illustrative model. b Presentation in XZ'-plane

$\frac{a_{R 1}\left(r_{\varepsilon}\right)}{a_{R 2}\left(r_{\varepsilon}=0\right)}$ and $\frac{a_{R 2}\left(r_{\varepsilon}\right)}{a_{R 2}\left(r_{\varepsilon}=0\right)}[\%]$. The dependence is presented as the function of tool nose radius in the radius $r_{\varepsilon} \in(0.03 e-3$, $5.00 e-3)(\mathrm{m})$.

By Eqs. (13) and (15) plotted in Fig. 6b and substituting values $R_{1}$ and $R_{2}$, the dependencies shown in Table 2 are obtained.

To ensure proper threading, the accelerations $a_{R 1}$ and $a_{R 2}$ should not exceed the acceleration value $a_{M}$ specified for a given machine. It was assumed that machining is most efficient when the greater value from $a_{R 1}, a_{R 2}$ is equal to

$a_{M}=\max \left\{a_{R 1}, a_{R 2}\right\}$

\subsection{Determination of the cutting width $a_{e}$ for a given roughness class}

The theoretical surface roughness depends on the cutting width $a_{e}$, geometry of the cutting edge, and the machined profile. The cutting width $a_{e}$, defined as the distance obtained by projecting tool points tangent with the machined surface profile on the Z-axis (Fig. 8a), should be constant for a given set of machining parameters. In rope threading, the defined cutting width $a_{e}$ is equal to the feed per revolution $f_{z}$. Since $a_{e}$ is the more general parameter, it was chosen to determine the roughness. Simulations were used to determine the maximum cutting width values $a_{e}$ to obtain the required roughness class for different values of the nose radius $r_{\varepsilon}$. For cutting tools with a nose radius of $r_{\varepsilon}<2 e-$ $3(\mathrm{~m})$, the geometry from Fig. 7a was assumed, where the tool end cutting edge angle and the side cutting edge angle were $30^{\circ}$. For cutting tools with a larger radius $r_{\varepsilon}$, the geometry from Fig. 7b was used. Further calculations adopted the simplification that the influence of the roughness on the diameter $d$ is negligibly small and that the cutting edge during machining is tangent to the thread contour.

The thread contour's inclination angle $\alpha$ varies during machining. Consequently, a constant cutting width $a_{e}$ results in varied roughness. For a given feed per revolution, the roughness $R z$ was defined by Eq. (17) and Fig. 8a. The case $R z_{2}$ with a horizontal line is a theoretical, non-existent case of the analyzed thread contour due to the finite value of the radius values. In such $R z$ definition, the curved contour of the thread is neglected.

$R z=\max \left\{R z_{1}, R z_{2}, R z_{3}\right\}$

Equation (17) was used to determine the cutting width $a_{e}$ required for a given class of roughness. The calculations were repeated for different nose radii $r_{\varepsilon}$. Results are presented in Fig. $8 \mathrm{~b}$.

The curves plotted in Fig. $8 \mathrm{~b}$ can be used to determine the cutting width $a_{e}$ for a given nose radius to obtain a required roughness class.
Fig. 5 Absolute accelerations in the $\mathrm{X}$-axis on arcs for: $r_{\varepsilon}=0.25 e$ $-3(\mathrm{~m}), n=1000$ (rpm). a Values of $\left|a_{x 1}\right|$ in the function of angle $\beta_{1} \in(0, \alpha)$. b Instantaneous and average values of $\left|a_{x 2}\right|$ on arc, in the time domain for $f_{z}=0.1 e-$ $3(\mathrm{~m})$ a

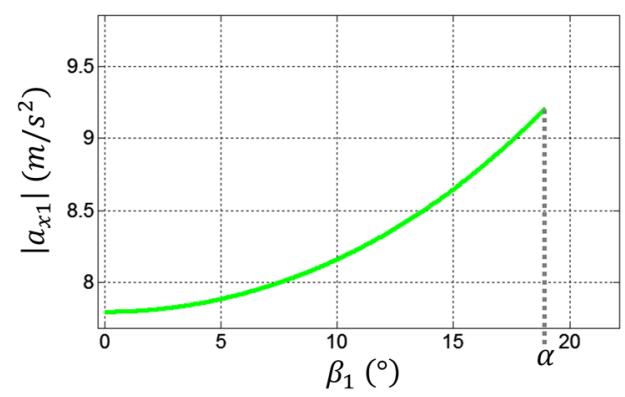

b

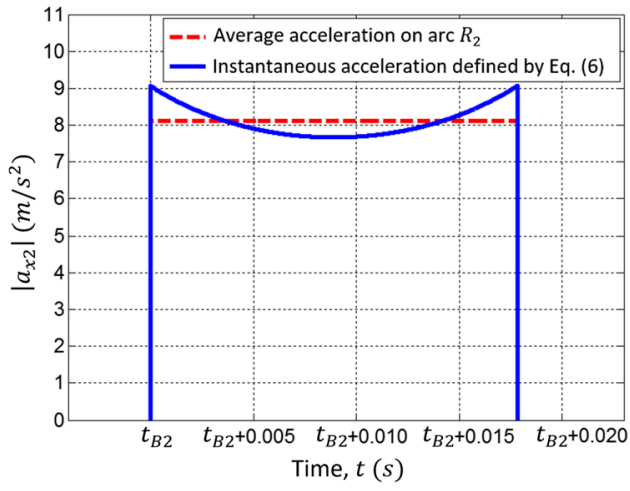



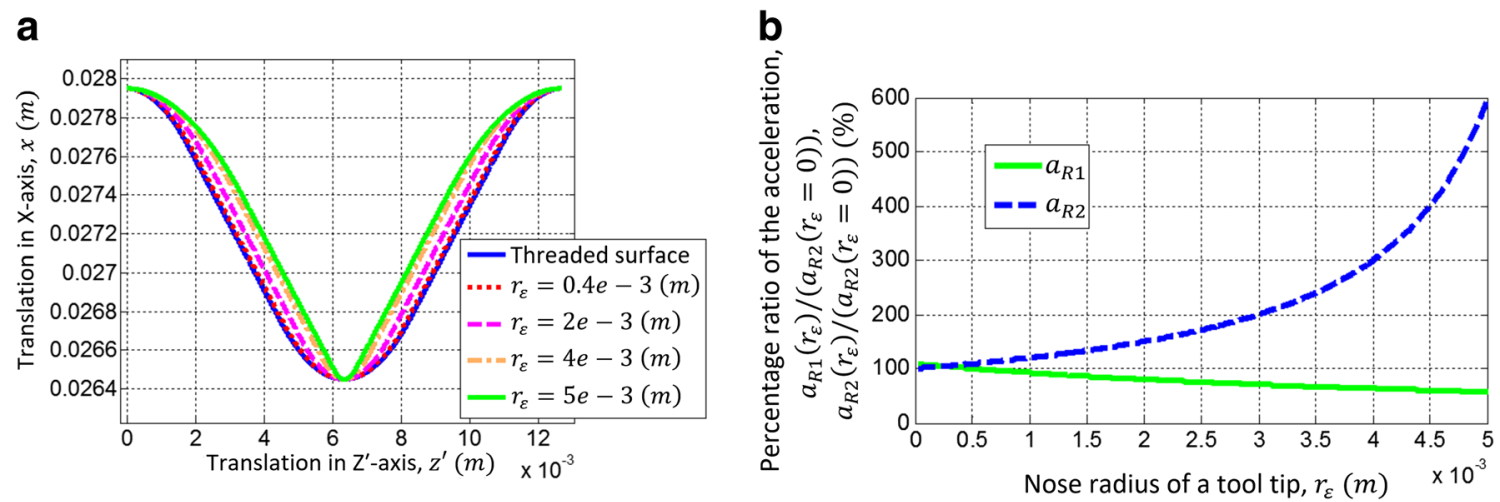

Fig. 6 Effect of the nose radius on the tool path in rope threading. a Tool movement in the X-axis for varied values of the tool nose radius. $\mathbf{b}$ Relative accelerations $a_{R 1}$ and $a_{R 2}$ as a function of the tool nose radius $r_{\varepsilon}$

Note that in the case of high cutting width values, the thread profile may not be achieved (Fig. 9). Therefore, it is not recommended to use high nose radius values for high $R z$. When the $a_{e}$ value increases, the thread profile may be increasingly flattened because of the material that is not machined. Therefore, the profile accuracy can be added as an additional constraint.

\section{Performance optimization of rope threading}

\subsection{A rope threading model that does not account for tool life}

To obtain the maximum efficiency, the time $t_{1}(\mathrm{~min})$, described by Eq. (18), should be as short as possible. Given a constant length $l(\mathrm{~m})$ of a machined thread, time reduction is equivalent to maximizing the efficiency function defined as $t_{1}^{-1}$, as shown in Eq. (19)

$t_{1}=\frac{l}{f_{z} \cdot n} \rightarrow \min$

$t_{1}^{-1}=\frac{f_{z} \cdot n}{l} \rightarrow \max$

In rope threading, the maximum rotational spindle speed $n_{a \text { max }}$ derived by a given acceleration $a_{M}$ can be derived from Eqs. (13) and (15) by substituting $a_{M}$ into $a_{R 1}$ and $a_{R 2}$

$n_{a \max }=60 \cdot \sqrt{a_{M}\left(R_{1}+r_{\varepsilon}\right) \cdot \frac{\cos (\alpha)}{\left(P-f_{z}\right)^{2}}}$, for $\quad r_{\varepsilon} \leq 0.25 e^{-3}(\mathrm{~m})$

$n_{\text {amax }}=60 \cdot \sqrt{a_{M}\left(R_{2}-r_{\varepsilon}\right) \cdot \frac{\cos (\alpha)}{\left(P-f_{z}\right)^{2}}}$, for $\quad r_{\varepsilon}>0.25 e^{-3}(\mathrm{~m})$
To obtain a required class of roughness $R z$ for exemplary tools given tool nose radius $r_{\varepsilon}$, Fig. $8 \mathrm{~b}$ can be used to read the defined cutting width values $a_{e}$ that are equal to $f_{z}$ in rope threading. After substituting the values into Eqs. (20) and (21), the value of $\mathrm{n}_{a \max }$ depends on: $\left(R z, r_{\varepsilon}\right.$, and $\left.a_{M}\right)$.

Apart from machine acceleration $a_{M}$, the cutting speed $v_{c}$ is another constraint on the rotational spindle speed $n$ both in the upper and lower bands.

The $v_{c}$ values change during machining because of dimension $h$, which must be taken into account if these changes significantly affect the cutting speed $v_{c}$.

For further calculations in the paper, we assumed $v_{c \min }=30\left(\frac{\mathrm{m}}{\mathrm{min}}\right)$ and $v_{c \max }=100\left(\frac{\mathrm{m}}{\mathrm{min}}\right)$.

The maximum rotational spindle speed instead of $n_{a \text { max }}$ is also constrained by $v_{c \min }$ and $v_{c \max }$, which corresponds to $n_{\text {min }}$ and $n_{v \text { max }}$, respectively. It results, that the maximum rotational spindle speed is equal to

$n_{\max }=\min \left\{n_{a \max }, n_{v \max }\right\}$

and the condition

$n_{a \max } \geq n_{\min }$

has to be satisfied also.

The maximum rotational spindle speed $n_{\max }$ as a function of $r_{\varepsilon}$ and $R z$ is shown in Fig. 10a. Graphs were plotted for thread diameters defined by the standard for three different lathes. Each lathe enabled machining with its particular tool acceleration characteristics in the X-axis- $a_{M}$. The graphs account for limitation resulting from the cutting speed $v_{c}$.

Figure 10b shows $t_{1}^{-1}$ values as a function of the selected roughness class $R z$ and nose radius $r_{\varepsilon}$.

The data from Fig. 10b can be used to determine nose radius of a cutting tool $r_{\varepsilon}$ for a selected roughness class to ensure the highest efficiency of machining. 
Table 2 Dependence between accelerations $a_{R 1}$ and $a_{R 2}$ for a given $r_{\varepsilon}$

$r_{\varepsilon}<\frac{R 1-R 2}{2}=0.25 e^{-3}(\mathrm{~m})$

$r_{\varepsilon}=\frac{R 1-R 2}{2}=0.25 e^{-3}(\mathrm{~m})$

$r_{\varepsilon}>\frac{R 1-R 2}{2}=0.25 e^{-3}(\mathrm{~m})$

$a_{R 1}>a_{R 2}$

$a_{R 1}=a_{R 2}$

$a_{R 1}<a_{R 2}$

\subsection{Considering the tool life dependent on the cutting speed $v_{c}$ in rope threading}

The tool life is a factor to be considered when planning the mass production of threads. Equations describing it were proposed by F. W. Taylor. A tool operating at a higher cutting speed has a shorter lifetime. The minimization of the machining time $t_{2}$ accounting for the tool life relative to the cutting speed $v_{c}$ is given by

$t_{2}=\frac{l}{f_{z} \cdot n}+\frac{t_{e}}{n_{T}} \rightarrow \min$

$n_{T}=\frac{T_{v}}{t_{1}}$

$T_{v}=\left(\frac{v_{c}}{C_{v}}\right)^{k}$

The optimum tool life is given by

$T_{v q}=(-k-1) \cdot t_{e}$

Using $v_{c}$ definition and Eqs. (26) and (27), we obtain the optimum rotational spindle speed $n_{\text {opt }} T_{v}$ when the tool life is taken into account

$n_{\text {opt } T_{v}}=\frac{1000 \cdot C_{v} \cdot\left((-k-1) \cdot t_{e}\right)^{\frac{1}{k}}}{\pi \cdot d}$

We emphasize that values $n_{\text {opt }} T_{v}$ are not always feasible due to constraints imposed on $a_{M}$ or $v_{c}$ max. Values can be considered optimum ones if (and only if) they do not exceed $n_{\max }$. Therefore, the optimum rotational spindle speed that accounts for tool tip lifetime $T_{v}$ for a given set of machining parameters can be given as

$n_{\text {opt } v}=\min \left\{n_{\max }, n_{\text {opt }}\right\}$

Figure 11a shows values of $n_{\max }, n_{\text {opt }}$, for three analyzed values $a_{M}$ and thread diameters given by the standard. The inverse values of machining times (efficiency), with and without considering the tool life: $t_{1}^{-1}$ and $t_{2}^{-1}$, for the $a_{M}=10\left(\frac{\mathrm{m}}{\mathrm{s}^{2}}\right)$, $d 3=27.95(\mathrm{~mm})$ are presented in Fig. 11 .

Figure $11 \mathrm{~b}$ shows that when tool life is neglected, the most efficient machining for a roughness class of $R z=400(\mu \mathrm{m})$ occurs for $r_{\varepsilon}=4 e-3(\mathrm{~m})$. When the tool life is taken into consideration, the most efficient machining is obtained with a nose radius of $r_{\varepsilon}=5 e-3(\mathrm{~m})$. Differences in machining efficiency using tools with various $r_{\varepsilon}$ are significant, particularly between a tool with $r_{\varepsilon}=4 e-3(\mathrm{~m})$ and a tool with $r_{\varepsilon}=$ $2 e-3(\mathrm{~m})$.

\subsection{Accounting for the tool life dependent on the cutting speed $v_{c}$ and feed $f_{z}$ in rope threading}

One of the extended forms of tool life equations takes into consideration the cutting speed $v_{c}$ and - to a lesser degreethe feed per revolution $f_{z}$. The machining time given the additional effect of feed on the tool life can be defined by $t_{2}$, as in Eq. (24). Equation (26), which defined the tool life $T_{v}$, takes a different form for this case

$T_{v, f}=\left(\frac{v_{c}}{C_{v}}\right)^{k} \cdot f_{z}^{y_{T}}$

Similarly, as in the previous case, we obtain optimum rotational speed, given that

$n_{o p t T_{v, f}}=\frac{1000 \cdot C_{v} \cdot\left((-k-1) \cdot t_{e}\right)^{\frac{1}{k}}}{\pi \cdot d \cdot f_{z}^{\frac{y_{x}}{k}}}$

When considering the effect of the cutting speed and feed on the tool life, the optimum rotational spindle speed that does not exceed the permissible acceleration is given by

$n_{\text {opt } v, f}=\min \left\{n_{\max }, n_{\text {opt }} T_{v, f}\right\}$

Figure 12a shows graphs of $n_{\max }$ and $n_{\text {opt }} T_{v, f}$. Efficiency values $t_{2}^{-1}$ corresponding to the rotational spindle speed $n_{\text {opt }} T_{v, f}$ are presented in Fig. 12b.

\section{Analysis of machining methods: rope/standard/hybrid threading}

\subsection{Description of the methods}

Given the number of tool passes $m$, three machining types can be distinguished, as shown in Fig. 13. First is rope threading, where a complete thread is machined in one tool pass (Fig. 13a). Second is standard thread machining, where the number of tool passes is equal to the pitch divided by the cutting width $a_{e}$ (Fig. 13b). Third is hybrid threading, where a thread is machined in more than one pass but the number of passes required is smaller than that in standard threading (Fig. 13c). The diagrams in Fig. 13 relate to the XZ-plane 
Fig. 7 Tool geometry types. a For cutting tools with a radius $r_{\varepsilon}$ less than $2(\mathrm{~mm})$. b For cutting tools with a radius greater than or equal to $2(\mathrm{~mm})$

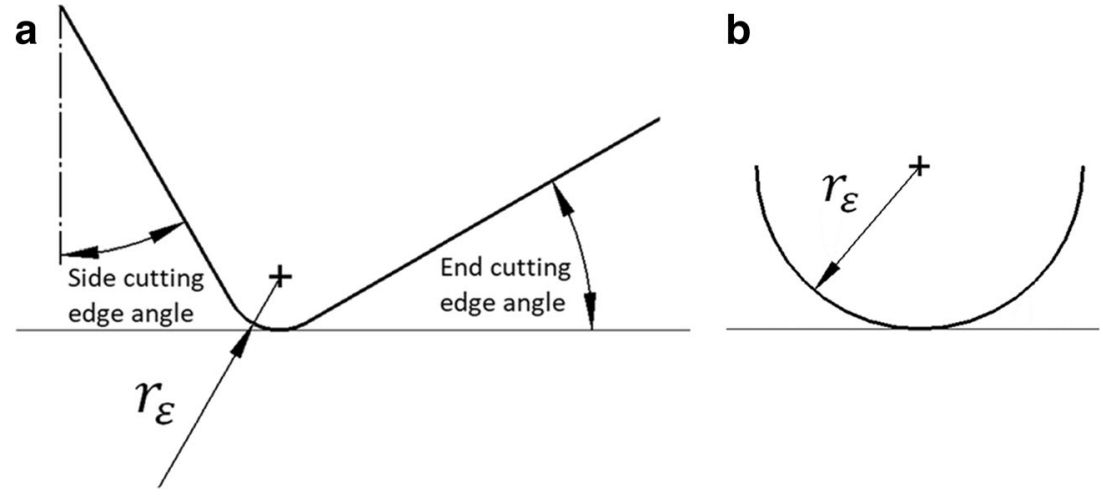

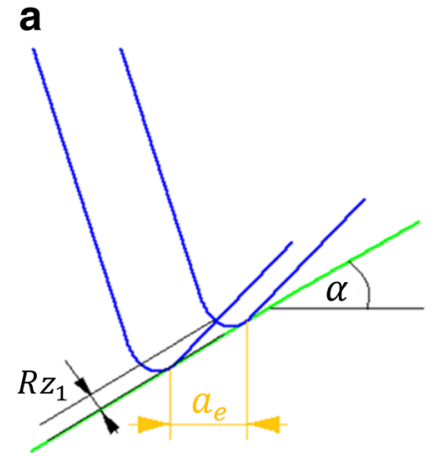
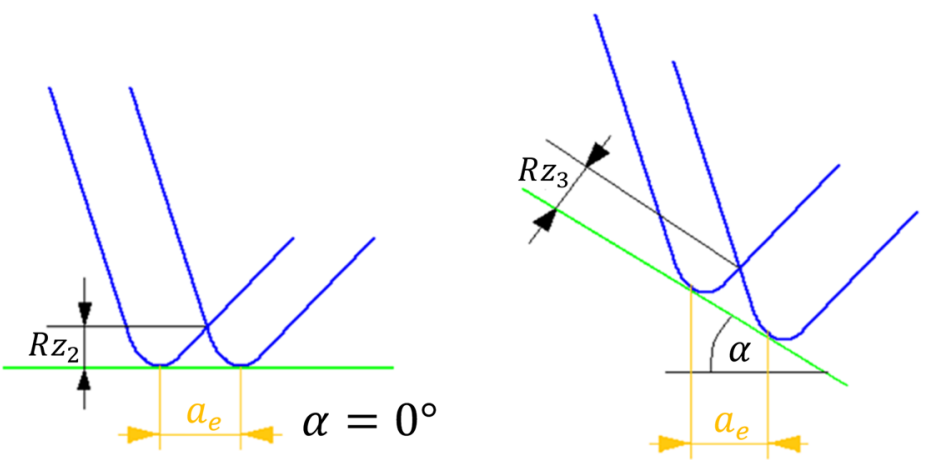

b

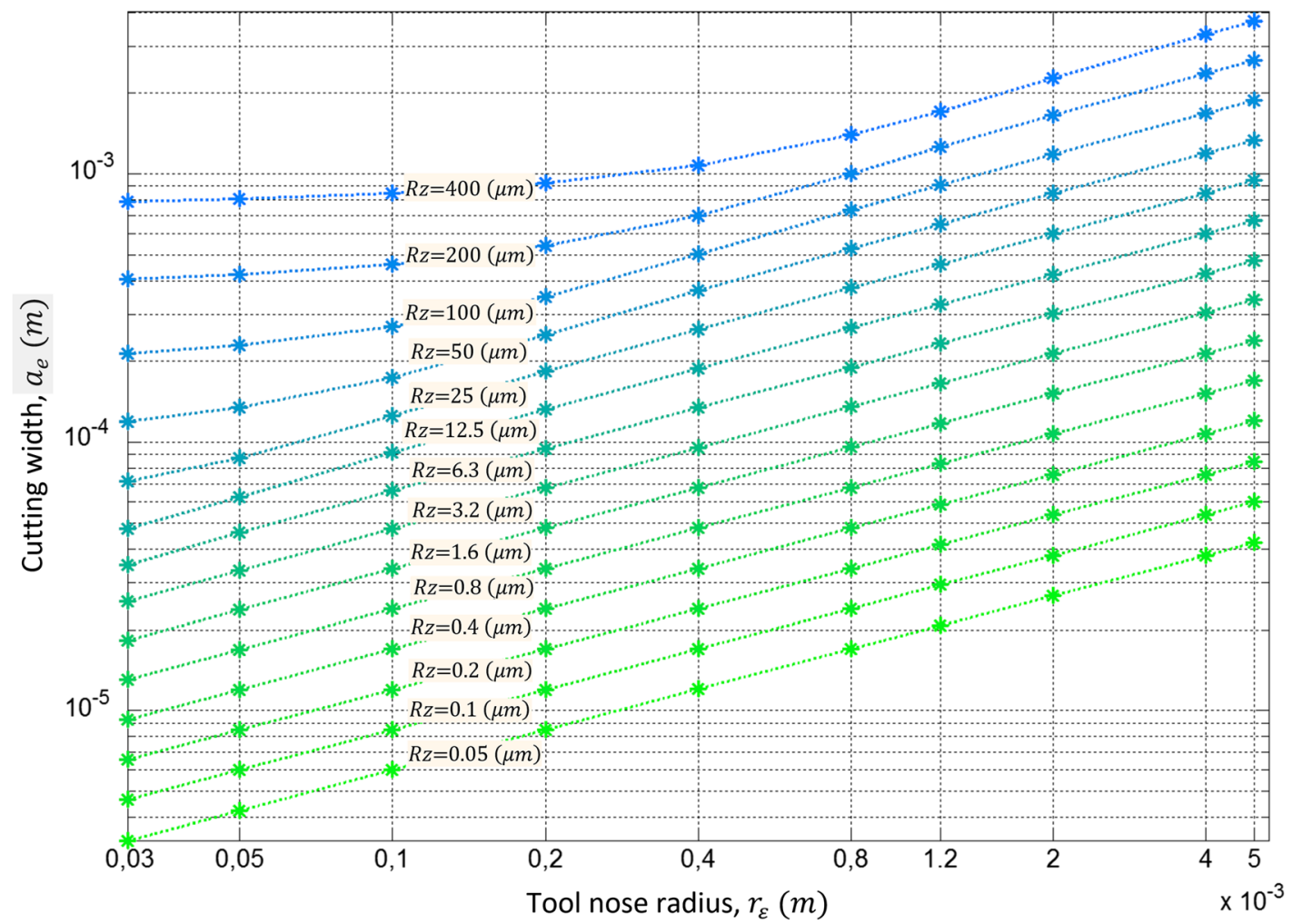

Fig. 8 Theoretical roughness values and cutting width values. a Determination of the theoretical roughness. b Defined cutting width values $a_{e}$ for given roughness classes $R z$ as a function of the nose radius $r_{\varepsilon}$ 


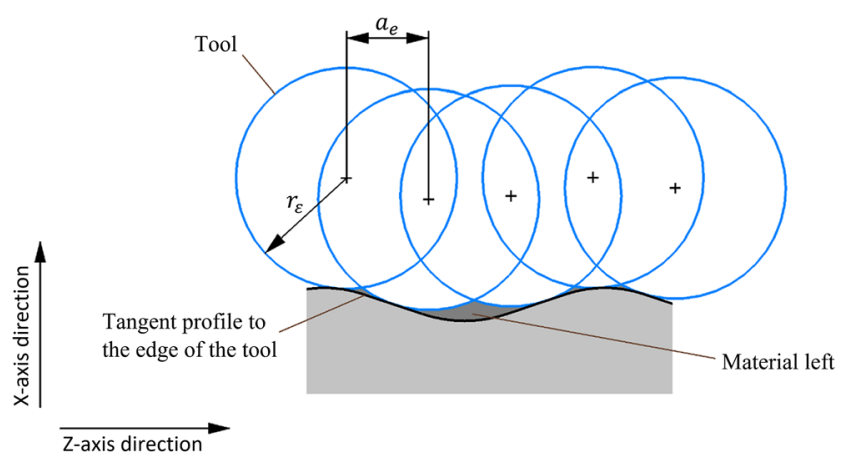

Fig. 9 Defined cutting width values $a_{e}$ for given roughness classes $R z$ as a function of the nose radius $r_{\varepsilon}$

and are only illustrative (the actual geometrical relationships of the analyzed thread are not retained).

\subsection{Machining in $m$-passes, without accounting for tool life}

Equation (33) defines the time $t_{3}(\mathrm{~min})$ required to machine a thread in $m$-passes without considering the tool life

$$
t_{3}=\frac{l}{m \cdot a_{e} \cdot n} \cdot m+(m-1) \cdot\left(\frac{l}{v_{m}}+2 t_{p}\right)
$$

Inequality (34) indicates when it is beneficial to increase the number of passes by $u$

$$
t_{3}(m+u)-t_{3}(m)<0
$$

Substituting values from Eq. (33) to Eq. (34), we obtain

$$
\begin{aligned}
& \frac{l}{(m+u) \cdot a_{e} \cdot n^{\prime \prime}} \cdot(m+u) \\
& \quad+(m-1+u) \cdot\left(\frac{l}{v_{m}}+2 t_{p}\right)-\left(\frac{l}{m \cdot a_{e} \cdot n^{\prime}} \cdot m+(m-1) \cdot\left(\frac{l}{v_{m}}+2 t_{p}\right)\right)<0
\end{aligned}
$$

where

$$
n^{\prime \prime}=60 \cdot \sqrt{a_{M}\left(R \pm r_{\varepsilon}\right) \cdot \frac{\cos (\alpha)}{\left(P-(m+u) \cdot a_{e}\right)^{2}}}
$$
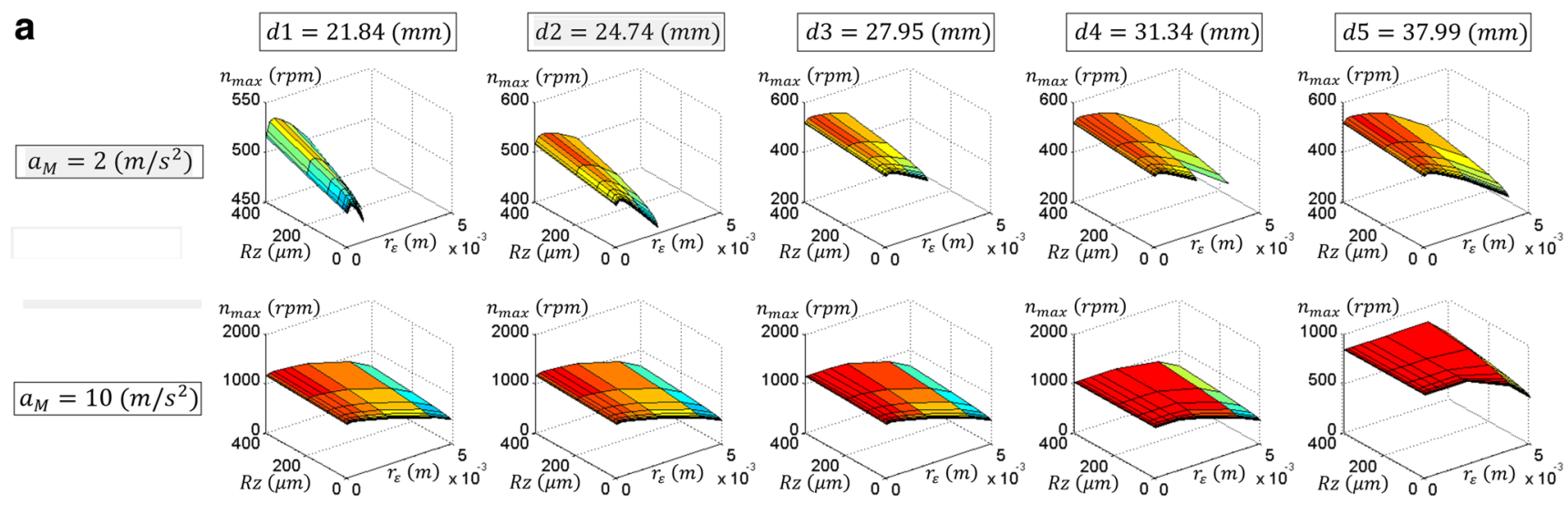

b

$$
d 1=21.84(\mathrm{~mm})
$$

$$
d 2=24.74(\mathrm{~mm})
$$
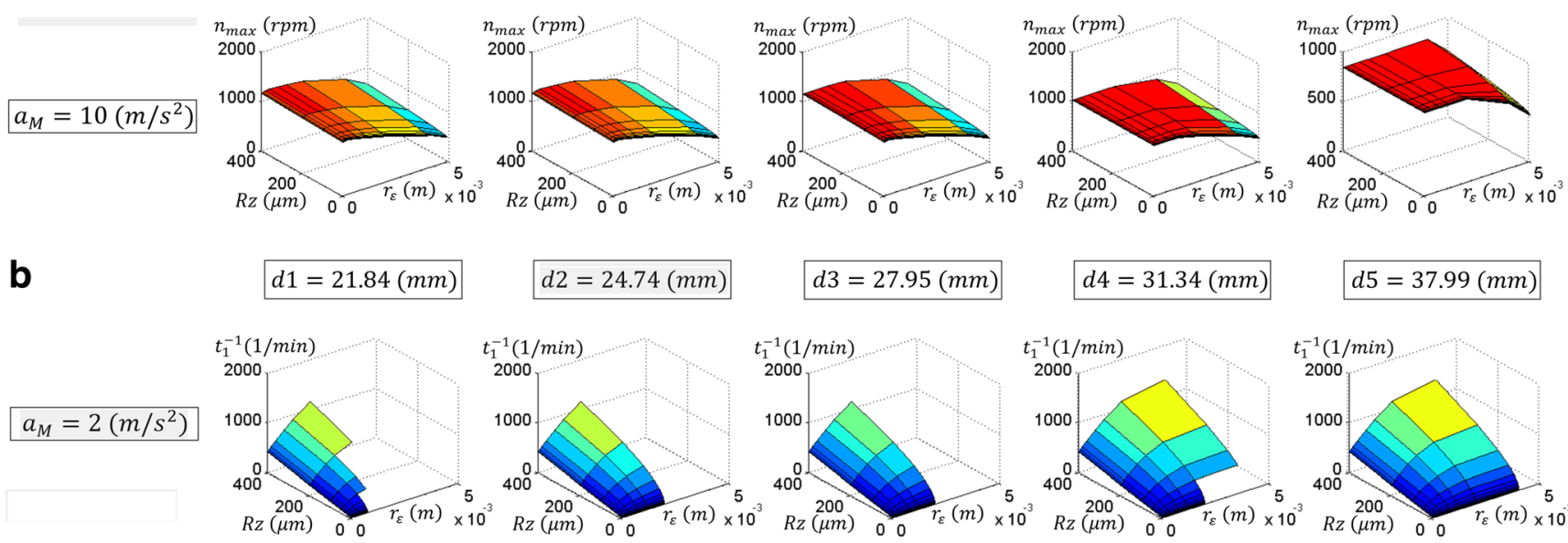

\section{$d 3=27.95(\mathrm{~mm})$}

$$
d 4=31.34(\mathrm{~mm})
$$

$d 5=37.99(\mathrm{~mm})$
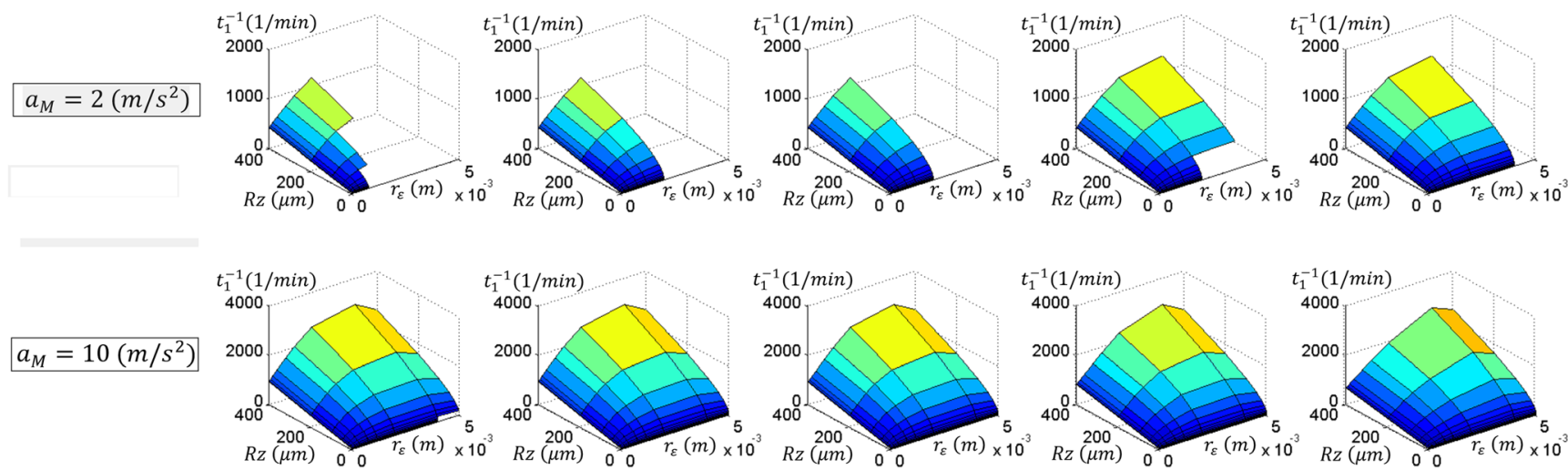

radius $r_{\varepsilon}$. b Efficiency values $t_{1}^{-1}$ as a function of the selected roughness class $R z$ and nose radius $r_{\varepsilon}$, for thread length $l=1(\mathrm{~m})$ 

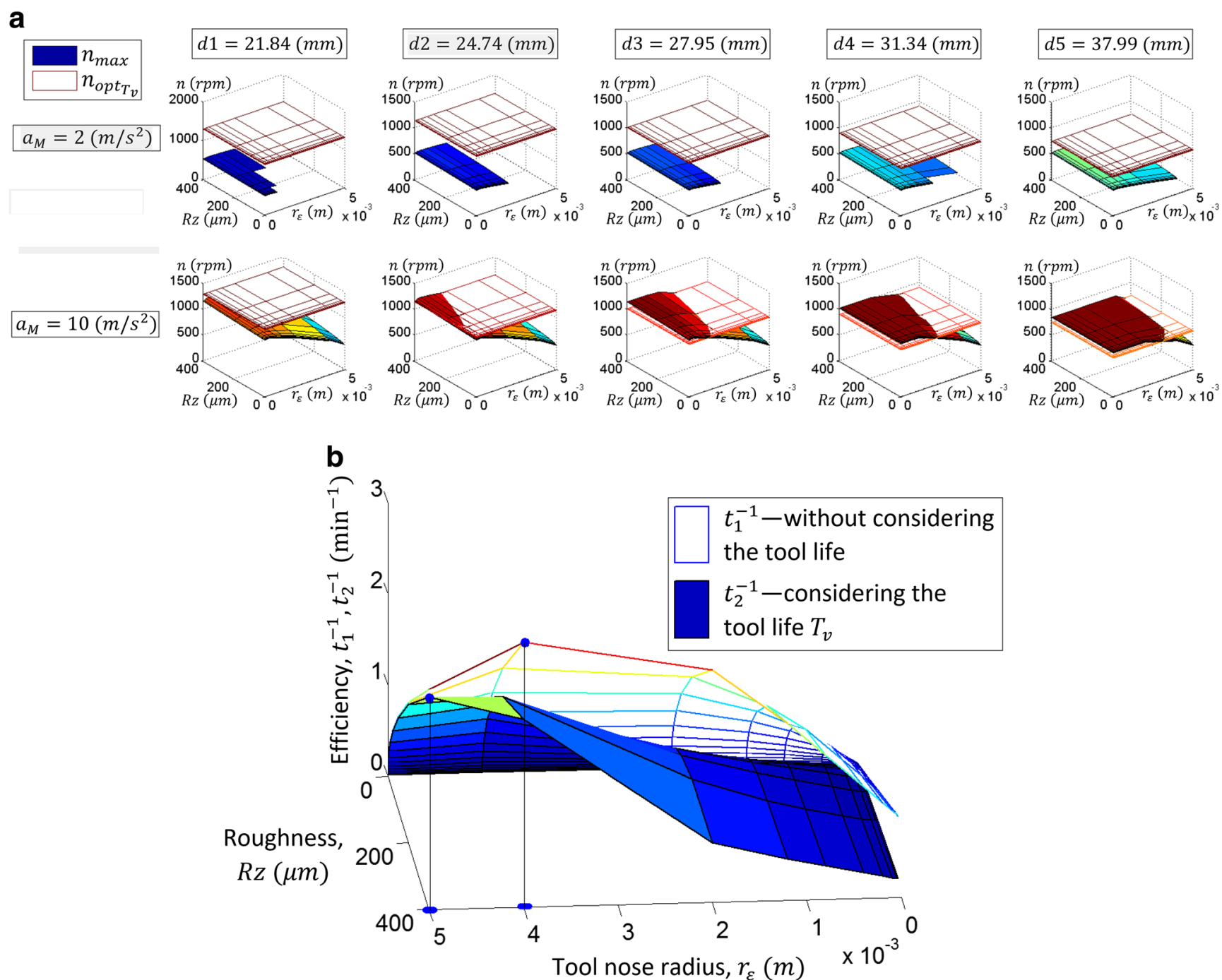

Fig. 11 Plots for rope threading model that allow to compare influence on some parameter values with consideration of the tool life dependent on the cutting speed $v_{c}$ in comparison to omitting it; $k=-8, C_{v}=150(\mathrm{~min})$, $t_{e}=10(\mathrm{~min}), l=1(\mathrm{~m})$. a Rotational spindle speeds: $n_{\max }$ and $n_{\mathrm{opt}} T_{v}$ for

$n^{\prime}=60 \cdot \sqrt{a_{M}\left(R \pm r_{\varepsilon}\right) \cdot \frac{\cos (\alpha)}{\left(P-m \cdot a_{e}\right)^{2}}}$

Having solved inequality (35), we obtain the condition that defines when it is favorable to increase the number of tool passes

$\frac{l}{60 \cdot \sqrt{a_{M}\left(R \pm r_{\varepsilon}\right) \cdot \cos (\alpha)}}>\frac{l}{v_{m}}+2 t_{p}$

The values $R \in\left\{R_{1}, R_{2}\right\}$ and sign \pm depend on the $r_{e}$ value, according to Table 2 .

Notably, neither the number of passes $m$ nor the difference in passes $u$ affects the final form of inequality (38).

This finding means that if inequality (38) is satisfied, it is worth increasing the number of passes as much as possible; hence, standard threading is the most efficient rope threading as a function of the selected roughness class $R z$ and nose radius $r_{\varepsilon}$. b Machining efficiency for $a_{M}=10\left(\frac{\mathrm{m}}{\mathrm{s}^{2}}\right), d 3=27.95(\mathrm{~mm})$ shown in a graphical analysis

method. If the inequality is not satisfied, the most efficient machining is conducted in one pass, corresponding to rope threading, and each additional pass increases the machining time.

Substituting the acceleration Eqs. (13) and (15) into inequality (38), we obtain

$\frac{l}{\left(P-a_{e}\right) \cdot n}>\frac{l}{v_{m}}+2 t_{p}$

The shortest machining time in the model with neglecting the tool life is achieved for rotational spindle speed equal to $n_{\max }$. The most efficient machining method corresponding to the cutting width $a_{e}$, rotational spindle speed $n_{\max }$, and other given parameter values - for the model with neglecting the tool life - is presented in Fig. 14a. 

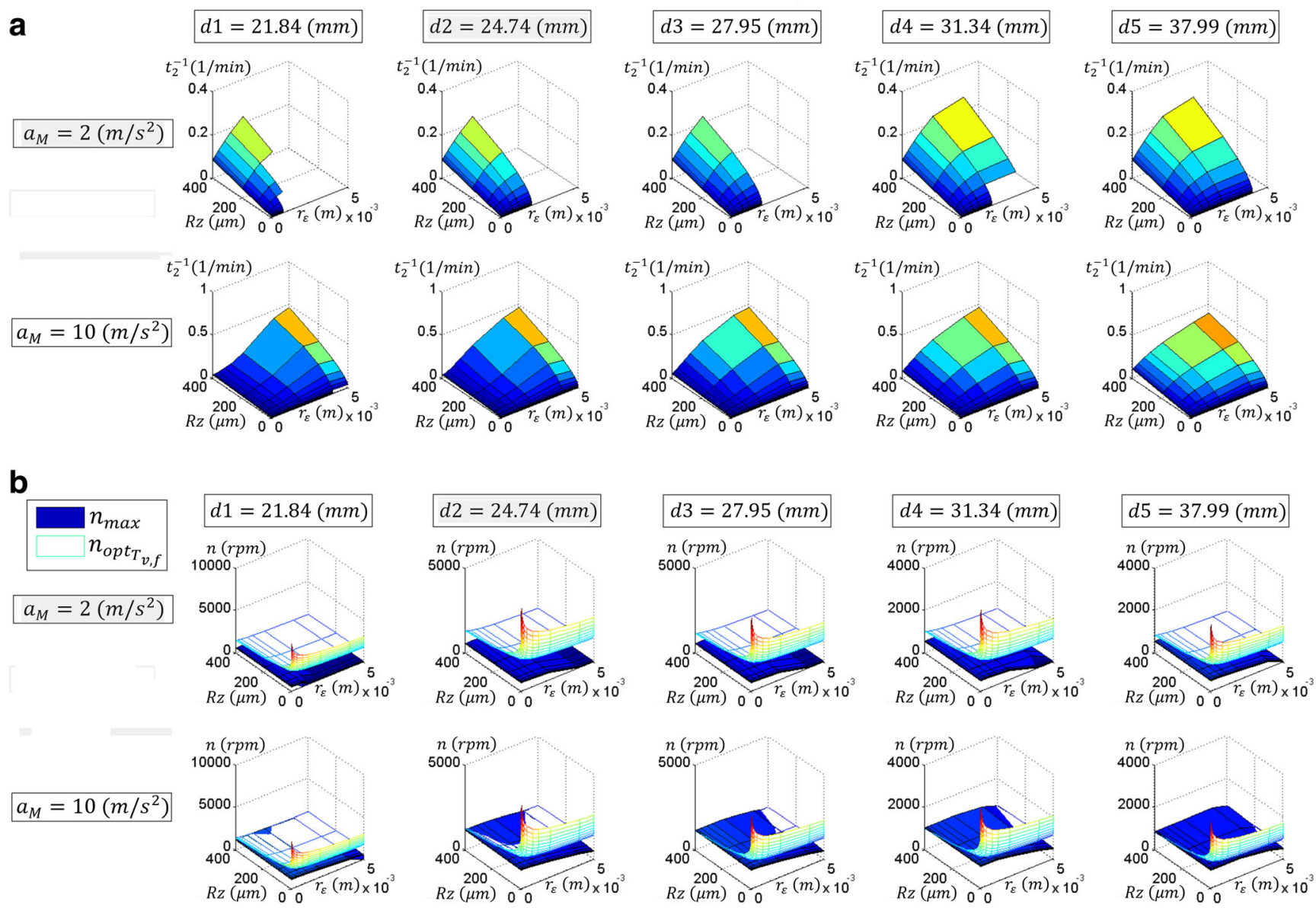

Fig. 12 Plots for rope threading model that does consider the tool life dependent on the cutting speed $v_{c}$ and feed $f_{z}$ as a function of the selected roughness class $R z$ and nose radius $r_{\varepsilon} ; k=-8, C_{v}=150(\min ), t_{e}=$

\subsection{Machining in $m$-passes, accounting for tool life}

The machining time $t_{4}(\mathrm{~min})$ conducted in $m$-passes that accounts for tool life defined as $T_{v}$ or $T_{v, f}$ can be expressed as

$t_{4}=t_{3}+\frac{t_{e}}{n_{T}}$

Substituting Eq. (33) into (40) and using the definition of $n_{T}$, we obtain

$t_{4}=\frac{l}{a_{e} \cdot n^{\prime}}+(m-1) \cdot\left(\frac{l}{v_{m}}+2 t_{p}\right)+\frac{\frac{l}{a_{e} \cdot n^{\prime}} \cdot t_{e}}{T}$

Similar considerations as those for $t_{3}$ (Eqs. (34), (38), and (39)) can be made for $t_{4}$ regarding the benefits of increasing the number of tool passes. The most efficient machining method, for the model which account the tool life and for the given parameters is presented in Fig. 14b as a function $n_{\text {opt }}$ of $a_{e}$.

For areas of high rotational spindle speeds, the most efficient method is rope threading. In case of spindle speeds from

$10(\min ) l=1(\mathrm{~m})$ and $y_{T}=-2$. a Rotational spindle speeds $n_{\max }$ and $n_{\text {opt } T_{v, f}}$. b Efficiency values $t_{2}^{-1}$

lower areas, the most efficient machining method depends on the tool life consideration. When this factor is neglected, the solution is standard threading; otherwise, it can be one of the three methods. In the latter case, there is an optimum number of tool passes $m_{o p t} \in<1,\left\lfloor\frac{P}{a_{e}}\right\rfloor>, m_{o p t} \in\left\{m_{v}, m_{v}, f\right\}$ and optimum rotational speed $n_{\text {opt }}^{\prime} \in\left\{n_{\text {opt } 1}, n_{\text {opt } 1}, f\right\}$ to ensure the shortest time of machining $t_{4}$ for a given roughness class $\operatorname{Rz}\left(a_{e}\right)$.

The actual feed rate which should be entered into the lathe is $f_{z}=m_{\mathrm{opt}} \cdot a_{e}$, and the actual rotational spindle speed which should be set is $n_{\text {opt }}^{\prime}(42,43)$. The dependency between $n_{\text {opt } 1}$ and $n_{\text {opt }}^{\prime}$ given by the number of tool passes $m_{\text {opt }}$ can be derived from Eq. (37). Thus, Eq. (42) is obtained. When the calculated cutting speed $v_{c}$ is higher than $v_{c \text { max }}$, then $n_{\text {opt }}^{\prime}$ is defined by Eq. (43).

$n_{o p t}^{\prime}=\frac{\left(P-a_{e}\right) \cdot n_{o p t}}{P-m_{o p t} \cdot a_{e}}$, for $\pi \cdot d \cdot \frac{n_{o p t}^{\prime}}{1000} \leq v_{c \max }$

$n^{\prime}{ }_{o p t}=n_{v \max }=\frac{1000 \cdot v_{c \max }}{\pi \cdot d}$, for $v_{c}>v_{c \max }$ 


\section{a Rope threading}

$m=1 \quad m-1=0$ tool returns

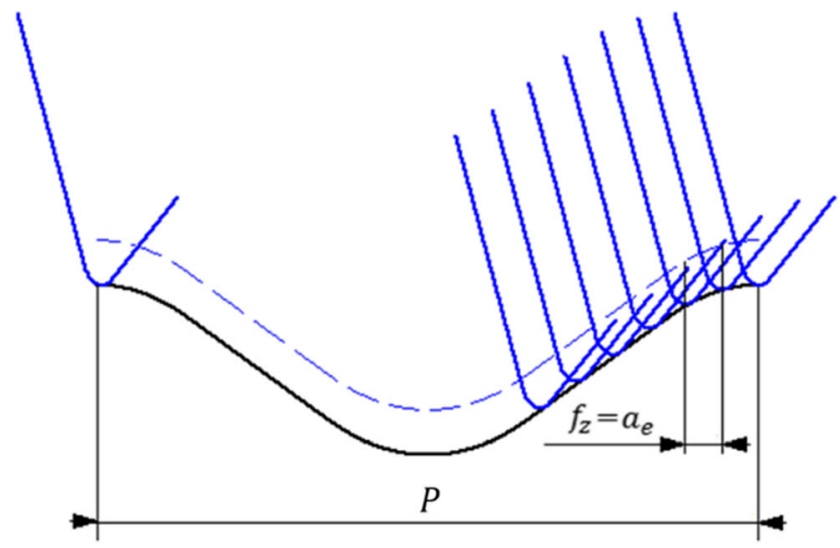

b
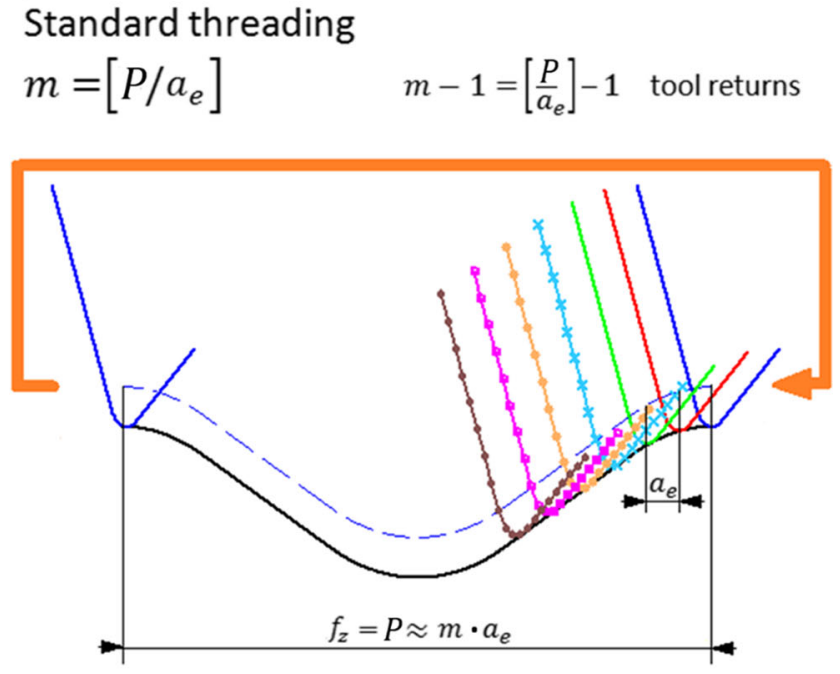

C

Hybrid threading

$1<m<\left[P / a_{e}\right]$ figure for: $m-1=2$ tool returns

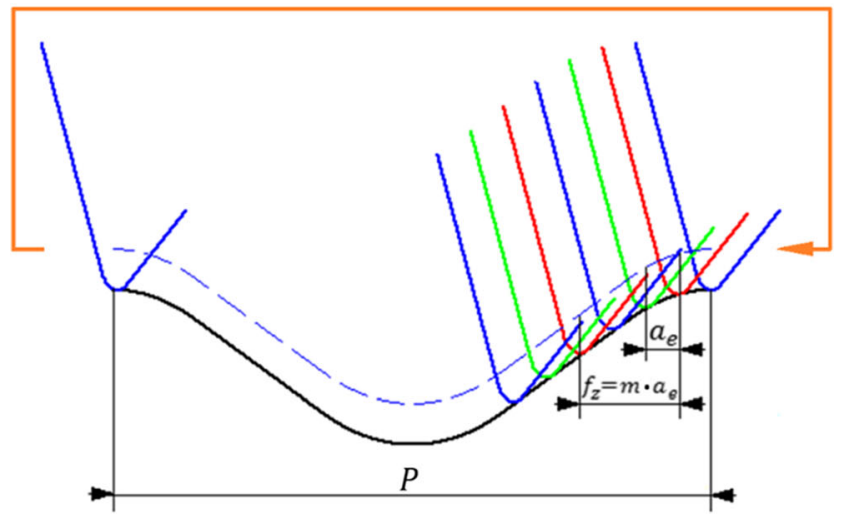

Fig. 13 Rope threading methods. a Rope threading. b Standard threading. c Hybrid threading

\section{Algorithm-based selection of cutting parameters and a threading method}

The algorithm presented below can be used to select the cutting parameters and threading method.

1. Determine $a_{M}, l, d$, the expected roughness class $R z, r_{\varepsilon}$ of available tools, range of permissible cutting speed $v_{c}$, and other possible machine limitations. Check the influence of $a_{e}$ values on the thread contour; this parameter can be constrained or taken into account later.

2. Select a model: Neglect the tool life and consider the effect of cutting speed $v_{c}$ on the tool life, or account for the effect of the cutting speed $v_{c}$ and feed per revolution $f_{z}$ on the tool life.

3. Calculate the optimum rotational spindle speed $n$ for rope threading. According to the model, use $n_{\max }(20)$ or (21), $n_{\text {opt } v}$ (29), and $n_{\text {opt } v, f}$ (32).

4. Calculate the efficiency function for the selected model. Select the nose radius $r_{\varepsilon}$, ensuring the most efficient machining for a required class of roughness. Determine the cutting width $a_{e}$ for the selected $r_{\varepsilon}$ and $R z$ in rope threading on the basis of Fig. $8 \mathrm{~b}$.

5. Select a machining method (standard, hybrid, rope threading) using Eq. (39) plotted for some exact values in Fig. 14, using the calculated optimum rotational spindle speed and the cutting width $a_{e}$ reading in rope threading. If $a_{e}$ is not constrained due to the correct thread profile, take that influence into account when choosing the optimum parameter values.

(a) When rope threading is the most efficient method, perform cutting with a spindle speed of $n_{\max }$ (20) or (21), $n_{\text {opt } v}$ (29), and $n_{\text {opt }}$, $f$ (32) depending on the selected model and with feed $f_{z}$ and a single tool pass with $m=1$.

(b) When standard threading is the most efficient method (the model neglects tool life), cut with $m=a_{e}$ tool passes with a rotational spindle speed $n^{\prime}$ (37) and a feed per revolution equal to the thread pitch.

(c) When the number of tool passes has not been clearly determined (the lower area of Fig. 14b), an optimum value from interval $m_{o p t} \in<1,\left\lfloor\frac{P}{a_{e}}\right\rfloor>$ should be found so that the machining time $t_{4}$ defined in Eq. (41) is minimized. Cut in $m$ opt tool passes with a rotational spindle speed of $n_{\text {opt }}^{\prime}$ (37) feed per revolution equal to $f_{z}=m_{\text {opt }} \cdot a_{e}$.

\section{Results}

The results presented in Figs. 15 and 16 were plotted for the smallest and largest thread diameters $d$ respectively, which are given by the standard (Table 1). 
Fig. 14 Most efficient machining method dependent on the cutting width $a_{e}$ and rotational spindle speed $n$, for $v_{m}=30\left(\frac{\mathrm{m}}{\mathrm{min}}\right)$, $t_{p}=\frac{1}{30}(\mathrm{~min})$, and $l=1(\mathrm{~m})$. a Not considering the tool life. $\mathbf{b}$ Considering the tool life

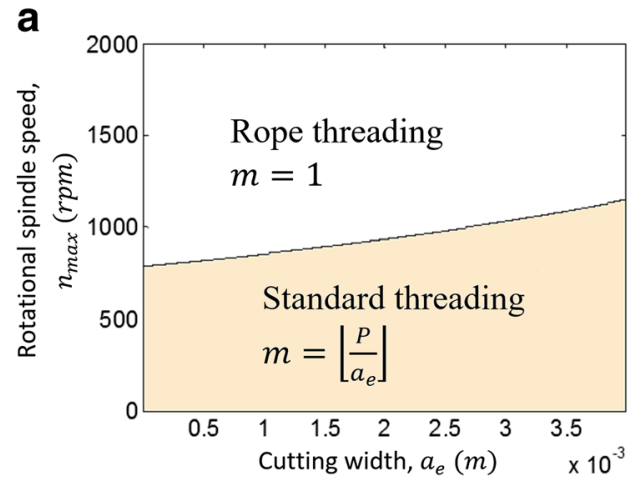

To show the findings with better clarity, the domain of functions (Figs. 15 and 16) is given by pairs of values defined by the roughness $R z$ and nose radius $r_{\varepsilon}-p\left(R z, r_{\varepsilon}\right)$, where $R z \in\{0.05$,

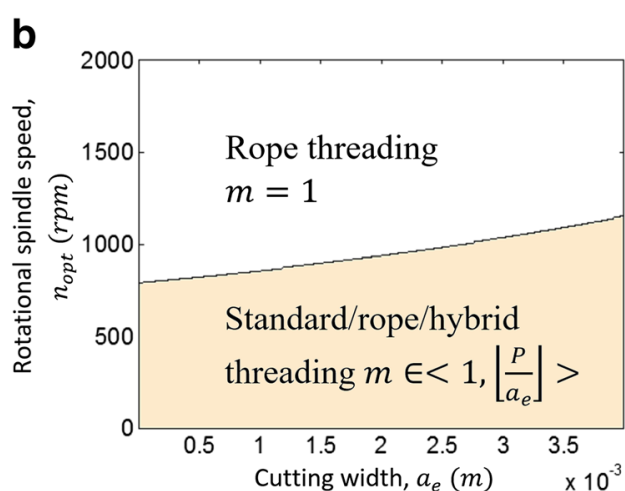

a

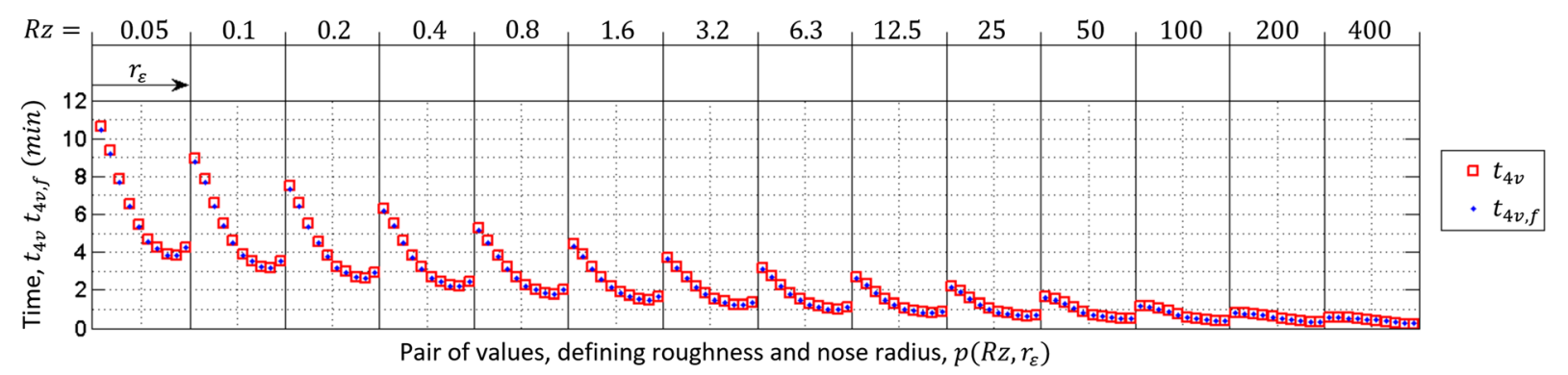

b

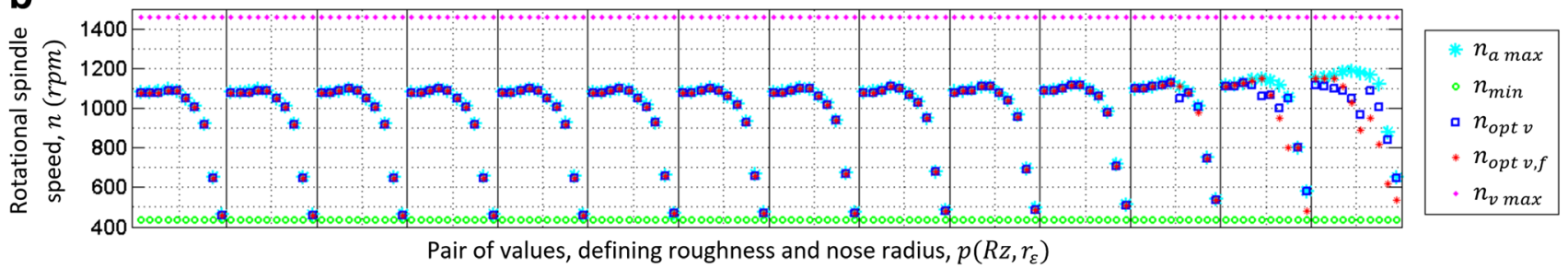

C

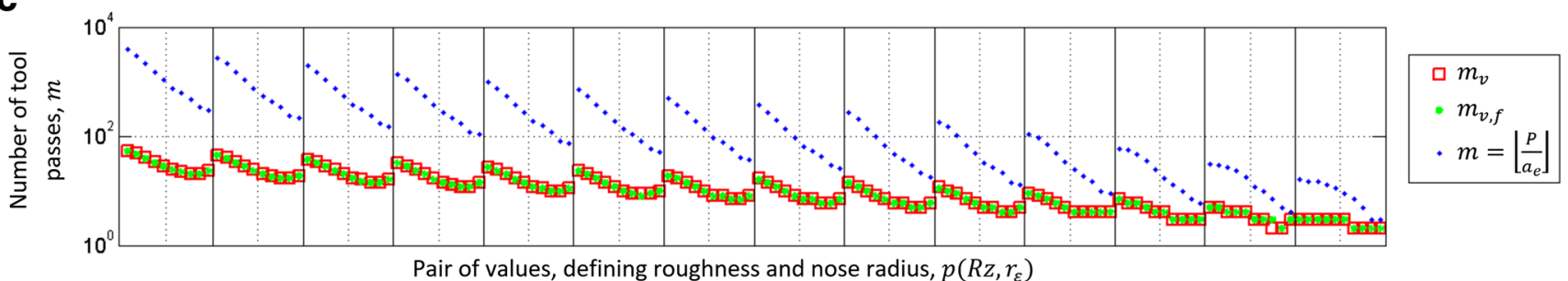

d

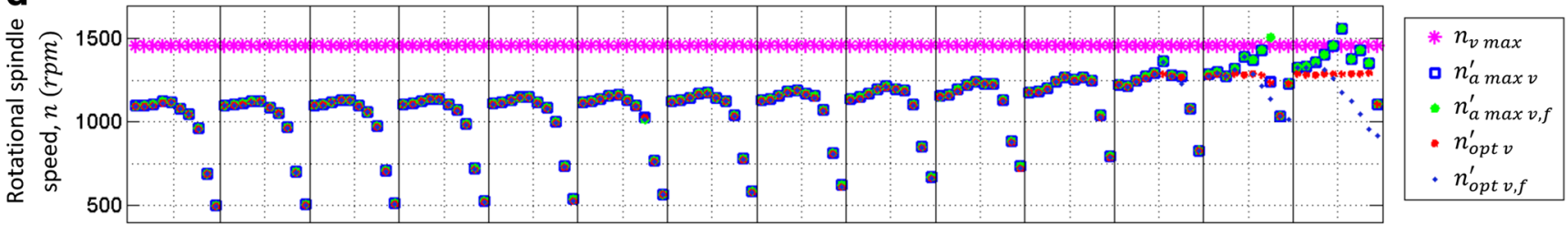

Pair of values, defining roughness and nose radius, $p\left(R z, r_{\varepsilon}\right)$

Fig. 15 Results for a thread defined by the standard with the smallest diameter $-d 1=21.84(\mathrm{~mm})$ as a function of successive pairs from the $p\left(R z, r_{\varepsilon}\right)$, for parameter values: $v_{m}=30\left(\frac{\mathrm{m}}{\mathrm{min}}\right), t_{p}=1 / 30(\mathrm{~min}), t_{e}=$ $10 \quad(\mathrm{~min}), \quad l=1 \quad(\mathrm{~m}), \quad k=-8, \quad C_{v}=150 \quad(\min ), \quad y_{T}=-2$, $v_{c} \in<30 ; 100>\left(\frac{m}{m i n}\right), a_{M}=10\left(\frac{m}{s^{2}}\right)$. a Shortest times corresponding to
$0.1,0.2,0.4,0.8,1.6,3.2,6.3,12,25,50,100,200,400\}$ and $r_{\varepsilon} \in\{0.03,0.05,0.1,0.2,0.4,0.8,1.2,2,4,5\}$. Note that roughness $R z$ values correspond to cutting width $a_{e}$ values (see Fig. 8b). 
a

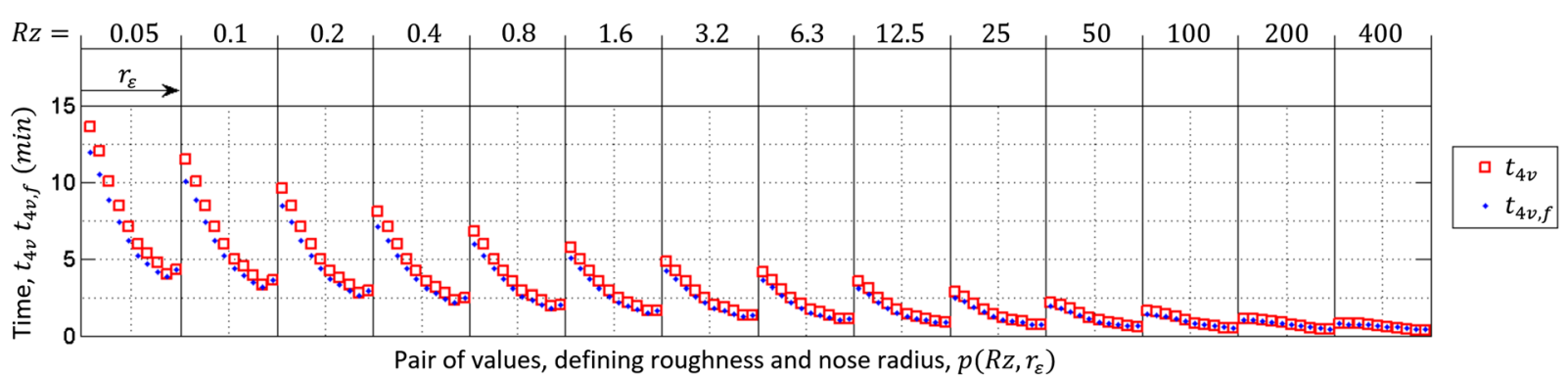

b
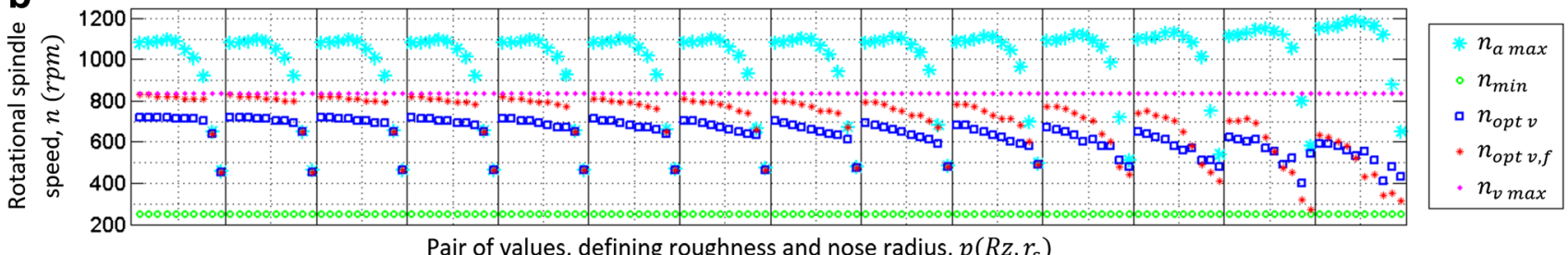

Pair of values, defining roughness and nose radius, $p\left(R z, r_{\varepsilon}\right)$

C

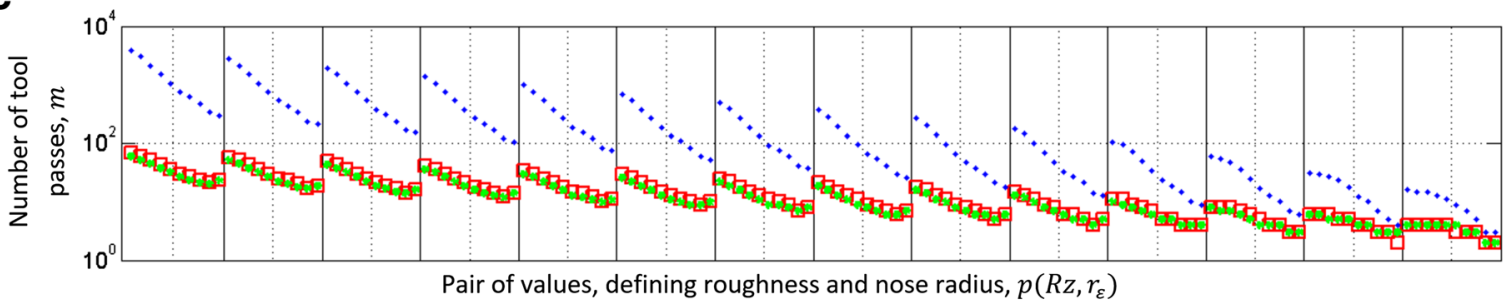

d

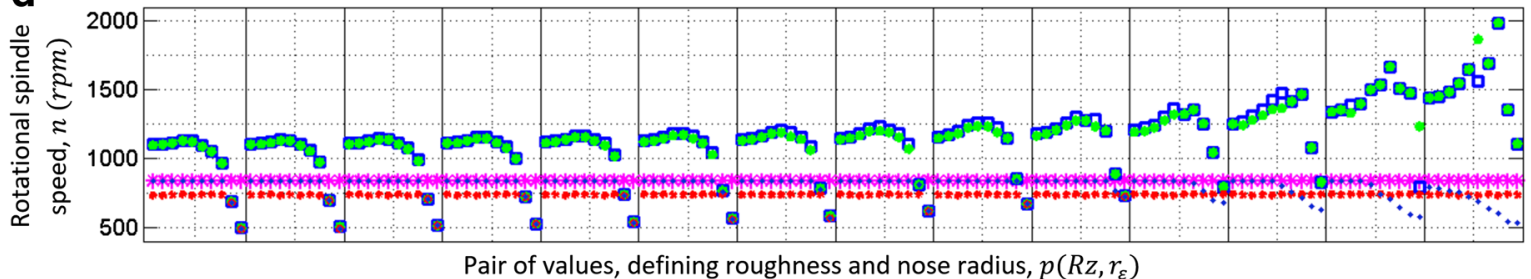

* $n_{v \max }$
- $n_{a \max v}^{\prime}$
- $n_{a \max v, f}^{\prime}$
- $n_{o p t v}^{\prime}$
- $n_{o p t v, f}^{\prime}$

Fig. 16 Results for a thread defined by the standard with the largest diameter- $d 5=37.99(\mathrm{~mm})$ as a function of successive pairs from the $p(R z$, $\left.r_{\varepsilon}\right)$, for parameter values: $v_{m}=30\left(\frac{m}{\min }\right), t_{p}=1 / 30(\mathrm{~min}), t_{e}=10(\mathrm{~min})$, $l=1(\mathrm{~m}), k=-8, C_{v}=150(\min ), y_{T}=-2, v_{c} \in(30 ; 100)\left(\frac{m}{m i n}\right)$, $a_{M}=10\left(\frac{m}{s_{2}}\right)$. a Shortest times corresponding to the optimum number of

A systematic search was conducted to find the optimum number of tool passes and rotational spindle speeds $n=n_{\text {min }}$, $n_{\text {min }}+10, n_{\text {min }}+20, \ldots, n_{\max }$ and $m=1,2, \ldots,\left\lfloor\frac{P}{a_{e}}\right\rfloor$.

Figures 15a and 16a show the shortest time values $t_{4}$ for the tool life defined as $T_{v}(26)-t_{4 v}$ and for tool life $T_{v}(30)-t_{4 v, f}$. The optimum rotational spindle speeds $n_{\text {opt v }}, n_{\text {opt v, f for } m=1}$ and the rotational spindle speed constraints $n_{\min }, n_{a \max }$, and $n_{v}$ ${ }_{\max }$ for rope threading are presented in Figs. $15 \mathrm{~b}$ and $16 \mathrm{~b}$. The optimum number of passes $m_{v}$ and $m_{v, f}$ and its $\left\lfloor\frac{P}{a_{e}}\right\rfloor$ value are presented in Figs. 15c and 16c. In Figs. 15d and 16d, the limitations of rotational spindle speed $n_{a \max v}^{\prime}$ and $n_{a \max , f}^{\prime}$ updated due to $m_{v}$ and $m_{v, f}$ are presented, together with the optimum values $n_{\text {opt } v}^{\prime}$ and $n_{\text {opt } v, f}^{\prime}$. tool passes and optimum rotational spindle speed for both models of tool life. b Rotational spindle speed. c Parameters describing the number of tool passes. d Optimum rotational spindle speeds for both models of tool life when machining with the optimum number of tool passes

The shortest times $t_{4 v}$ and $t_{4 v, f}$ obtained for diameter $d 1$ (Fig. 15a) were almost the same for a given pair $p\left(R z, r_{\varepsilon}\right)$. In most cases, the differences between tool life models were higher for $d 5$ (Fig. 16a). For the most pairs, especially with small values of $r_{\varepsilon}$ and $R z-t_{4 v}$ was higher than $t_{4 v, f}$ but for some cases with high $r_{\varepsilon}$ and $R z-t_{4 v, f}$, values were higher than $t_{4 v}$

The optimum values of rotational spindle speeds for $m=1$ in case of $d 1$ were mostly limited by $n_{a \text { max }}$ (Fig. 15b). The defined $n_{v \max }$ could be omitted in this case, because it was higher than $n_{a \max }$ for each pair. In some cases of high $R z$ values, $n_{\text {opt } v}$ and $n_{\text {opt } v, f}$ do not reach the maximum limited values. It was due to tool exchange time. For both considered thread diameters, the standard threading was not the most efficient machining in any considered case (Figs. 15c and 16c). For $d 1$ - in contrast to $d 5$ - the optimum number of tool 
passes $m_{v}$ and $m_{v, f}$ was the same for the given pair in most cases. In $d 5, m_{v}$ was higher than $m_{v, f}$ in most cases. The main limitation for $n_{\text {opt } v}^{\prime}$ and $n_{\text {opt } v, f}^{\prime}$ for $d 1$ was $n_{a \max v}^{\prime}$ and $n_{a \max }^{\prime}$ $v, f$, respectively, where both limitations had the same values for the most number of pairs (Fig. 15d). For d5, the most $n^{\prime}$ opt $v, f$ values were limited by $n_{v \text { max }}$. Some values of $n_{\text {opt } v}^{\prime}$ and $n_{\text {opt } v, f}^{\prime}$ for high $r_{\varepsilon}$ values and not very high $R z$ values were limited by $n_{v \text { max }}$ for the highest considered thread diameter. The values of $n_{\text {opt } v}^{\prime}$ were not limited by $n_{v \text { max }}$ in any case. When choosing the optimal solution, the thread profile contour accuracy must also be considered. It may be that the results of small $t_{4 v}$ and $t_{4} v_{f}$ achieved by high $R z$ and high $r_{\varepsilon}$ values do not fulfil the geometrical requirements or that the time saved relative to other solutions is not worth the degradation of geometric correctness.

\section{Conclusion}

The paper presents a thorough analysis of the noncircular turning process on the basis of the smooth-contour ISO 10208:1991 male rope thread. The optimization process results in the selection of the number of tool passes, which defines the threading method and the cutting parameter values. In the case of rope threading or hybrid threading, the increase in the tool nose radius value increases the required tool accelerations in the $\mathrm{X}$-axis. Relative to standard threading, the processing time is reduced for a smaller number of passes, but the cutting speed can be constrained by the machine tool acceleration capabilities. Surface roughness is considered along with an indication of the issue related to geometrical errors associated with excessively high cutting width values. The impact of tool life modelling is explored. The diameter of the machined thread also has an influence on the obtained values. Ultimately, algorithm-based selection of a threading method and cutting parameters is enabled. On the basis of the input parameter values and the model choice, the machining method can be selected along with the values of cutting parameters such as the number of passes, rotational spindle speed, tool nose radius, and feed per revolution in the Z-axis. The corresponding analysis shows the complexity of the machining of the rope threads mainly focusing on tool kinematics as a function of cutting parameters and tool geometry. Note that the analysis does not account for all phenomena that may influence the process; for instance, dynamic cutting forces are not taken into account.

Acknowledgements We acknowledge institute colleagues, particularly Dr. Inż. Krzysztof Filipowicz and Dr. Inż. Daniel Grochała, for their advice. We also thank Mr. Marek Stelmaszczyk for translating and proofreading, and AJE for English editing.
Funding information This work was financially supported by the National Centre for Research and Development (Project INNOTECH/ K3/IN3/18/226861/NCBR/14).

Open Access This article is distributed under the terms of the Creative Commons Attribution 4.0 International License (http:// creativecommons.org/licenses/by/4.0/), which permits unrestricted use, distribution, and reproduction in any medium, provided you give appropriate credit to the original author(s) and the source, provide a link to the Creative Commons license, and indicate if changes were made.

\section{References}

1. Sun Z, Tsao T-C (2008) Process feedback control of the noncircular turning process for camshaft machining. J Dyn Syst Meas Control 130:31006

2. Wang H, Yang S (2013) Design and control of a fast tool servo used in noncircular piston turning process. Mech Syst Signal Process 36: 87-94

3. Zhou H, Henson B, Wang X (2005) Extracted control approach for CNC non-circular turning. Asian J Control 7:50-55

4. Ma H, Tian J, Hu D (2013) Development of a fast tool servo in noncircular turning and its control. Mech Syst Signal Process 41: 705-713

5. Qiang L, Wu A, Bing C (2014) Variable angle compensation control of noncircular turning. Int J Adv Manuf Technol 70:735-746

6. Wu D, Chen K (2009) Design and analysis of precision active disturbance rejection control for noncircular turning process. Ind Electron IEEE Trans 56:2746-2753

7. Wu D, Chen K, Wang X (2007) Tracking control and active disturbance rejection with application to noncircular machining. Int $\mathrm{J}$ Mach Tools Manuf 47:2207-2217

8. Reddy RG, DeVor RE, Kapoor SG, Sun Z (2001) A mechanistic model-based force-feedback scheme for voice-coil actuated radial contour turning. Int J Mach Tools Manuf 41:1131-1147

9. $\mathrm{Ma} \mathrm{H}, \mathrm{Hu}$ D, Zhang K (2005) A fast tool feeding mechanism using piezoelectric actuators in noncircular turning. Int $\mathrm{J}$ Adv Manuf Technol 27:254-259

10. Hanson RD, Tsao T-C (2000) Periodic sampling interval repetitive control and its application to variable spindle speed noncircular turning process. J Dyn Syst Meas Control 122:560-566

11. Wu D, Chen K, Wang X (2009) An investigation of practical application of variable spindle speed machining to noncircular turning process. Int J Adv Manuf Technol 44:1094-1105

12. Lee BY, Tarng YS (2000) Cutting-parameter selection for maximizing production rate or minimizing production cost in multistage turning operations. J Mater Process Technol 105:61-66

13. WH p Y, Tarng YS (1998) Design optimization of cutting parameters for turning operations based on the Taguchi method. J Mater Process Technol 84:122-129

14. Paiva AP, Ferreira JR, Balestrassi PP (2007) A multivariate hybrid approach applied to AISI 52100 hardened steel turning optimization. J Mater Process Technol 189:26-35

15. Bhushan RK (2013) Optimization of cutting parameters for minimizing power consumption and maximizing tool life during machining of Al alloy SiC particle composites. J Clean Prod 39:242254

16. Hasçalık A, Çaydaş U (2008) Optimization of turning parameters for surface roughness and tool life based on the Taguchi method. Int J Adv Manuf Technol 38:896-903

17. Marksberry PW, Jawahir IS (2008) A comprehensive tool-wear/ tool-life performance model in the evaluation of NDM (near dry machining) for sustainable manufacturing. Int J Mach Tools Manuf 48:878-886 
18. Choudhury SK, Rao IVKA (1999) Optimization of cutting parameters for maximizing tool life. Int J Mach Tools Manuf 39:343-353

19. Gökkaya H, Nalbant M (2007) The effects of cutting tool geometry and processing parameters on the surface roughness of AISI 1030 steel. Mater Des 28:717-721

20. Neșeli S, Yaldız S, Türkeș E (2011) Optimization of tool geometry parameters for turning operations based on the response surface methodology. Measurement 44:580-587

21. Reddy NSK, Rao PV (2005) Selection of optimum tool geometry and cutting conditions using a surface roughness prediction model for end milling. Int J Adv Manuf Technol 26:1202-1210
22. Özel T, Hsu T-K, Zeren E (2005) Effects of cutting edge geometry, workpiece hardness, feed rate and cutting speed on surface roughness and forces in finish turning of hardened AISI H13 steel. Int J Adv Manuf Technol 25:262-269

Publisher's note Springer Nature remains neutral with regard to jurisdictional claims in published maps and institutional affiliations. 